\title{
Análise do emprego de armaduras treliçadas planas como alternativa tecnológica para a execução de vergas em alvenaria estrutural
}

\author{
Analysis of plane truss reinforcement as an alternative \\ technology for structural masonry lintels
}

\author{
Fabiana Martins de Rezende \\ Centro de Tecnologia \\ Universidade Federal de Santa Maria \\ Avenida Roraima, Prédio 07, Centro \\ de Tecnologia, Camobi \\ Santa Maria - RS - Brasil \\ CEP 97105-900 \\ Tel.: (55) 3220-8144 \\ E-mail: fabyeng@gmail.com
}

Gihad Mohamad Centro de Tecnologia Universidade Federal de Santa Maria Avenida Roraima, Prédio 07, Centro de Tecnologia, Camobi Santa Maria - RS - Brasil CEP $97105-900$ Tel.: (55) 3220-8144 E-mail: gihad@ufsm.br

Guilherme Aris Parsekian Departamento de Engenharia Civil, Centro de Ciências Exatas e de Tecnologia

Universidade Federal de São Carlos Rodovia Washington Luís, SP $310, \mathrm{Km}$

235, Parque Tecnológico Damha São Carlos - SP - Brasil CEP 13565-905 Tel.: (16) 3351-9657

E-mail: parsekian@ufscar.br

Eduardo Rizzatti Departamento de Estruturas e Construção Civil, Centro de Tecnologia

Universidade Federal de Santa Maria E-mail: edu_rizzatti@yahoo.com.br

Emil de Souza Sánchez Filho Programa de Pós-graduação em Engenharia Civil

Universidade Federal Fluminense

Rua Passo da Pátria, $156,3^{\circ}$ andar, sala 365 , Bloco D, São Domingos Niterói - RJ - Brasil CEP 24210-240

Tel.: (021) 2629-5410

E-mail: emilsanchez@uol.com.br

Recebido em 09/10/12

Aceito em 20/12/12

\section{Fabiana Martins de Rezende \\ Gihad Mohamad \\ Guilherme Aris Parsekian \\ Eduardo Rizzatti \\ Emil de Souza Sánchez Filho}

\section{Resumo}

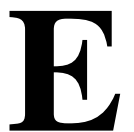

sse trabalho tem por objetivo avaliar o comportamento mecânico de vergas em alvenaria estrutural, executadas com blocos cerâmicos vazados, treliças planas e grampos verticais. O programa experimental consistiu na confecção de três modelos de vergas: vergas grauteadas, com armadura de flexão nas canaletas da abertura; vergas com blocos estruturais vazados e treliças planas; e vergas armadas com treliças planas e grampos verticais. Os resultados dos ensaios indicaram que as rupturas ocorreram por influência das tensões de cisalhamento, com fissuras inclinadas e esmagamentos na parte superior dos blocos. Os modelos grauteados resistiram a cargas maiores em relação aos demais. Contudo, os modelos com treliças planas e grampos verticais suportaram intensidades de forças maiores em relação apenas aos com treliças planas. $\mathrm{O}$ esforço cortante último resistido pelas vergas grauteadas foi inferior ao calculado a partir das recomendações da 15812-1 (ABNT, 2010) e NBR 15961-1 (ABNT, 2011). A verificação do esforço cortante último resistido pelas vergas com treliças planas e dos modelos com treliças planas e grampo, admitindo os mesmos limites de resistência ao cisalhamento estabelecido para as vergas grauteadas, permitiu concluir que, para o dimensionamento de vergas armadas na junta de assentamento, esses limites não podem ser aplicados, resultando em menores resistências.

Palavras-chave: Alvenaria estrutural. Vergas. Treliças Murfor. Blocos cerâmicos.

\section{Abstract}

The aim of this study is to evaluate the mechanical behavior of hollow clay block masonry beams reinforced with horizontal reinforcement truss, with or without vertical stirrups. In the experimental program, three types of beams were tested: a course of grouted blocks with reinforcement; beams with hollow blocks with plane truss reinforcement; and beams with plane truss with vertical stirrups. The test results indicated that most of the failures occur due to shear with inclined cracks and crushing of the blocks. The use of beams with grout demonstrated high levels of strength, when compared with the other models. The use of horizontal joint reinforcement with vertical stirrups led to higher failure values when compared to the beams with only joint reinforcement. The ultimate shear force measured on the tests of the beams was lower than the theoretical value calculated with NBR 15812-1 (ABNT, 2010) and NBR 15961-1 (ABNT, 2011). The expected failure loads of the beams with plane truss and plane truss with vertical stirrups, admitting the same limits of shear strength as the grouted beams, led to the conclusion that special provisions must be made to calculate the shear strength of masonry beams.

Keywords: Structural Masonry. Lintel. Murfor reinforcement masonry. Clay Block. 


\section{Introdução}

Atualmente no Brasil, o sistema construtivo em alvenaria estrutural está em franca expansão, em virtude de sua racionalização, rapidez de execução e otimização dos recursos materiais e humanos, que permitem a redução dos custos globais de construção. Nesse cenário de estabilização econômica em que vive o país, o aumento da competitividade e os avanços nas pesquisas são exigências fundamentais para uma maior confiabilidade e expansão das alternativas tecnológicas que podem ser empregadas para esse sistema construtivo. Segundo Lima (2010), mais de $80 \%$ de todas as unidades habitacionais populares construídas atualmente têm utilizado a técnica da alvenaria estrutural. Somente no estado do Rio Grande do Sul, 76\% dos empreendimentos concluídos em 2006 e financiados pela Caixa/RS foram construídos em alvenaria estrutural (RITCHER, 2007).

Nesse sistema construtivo é fundamental conceber os projetos em alvenaria estrutural considerando quais paredes serão estruturais ou não estruturais, conforme o projeto arquitetônico, de acordo com a tipologia da laje empregada. As principais ações verticais são oriundas do peso-próprio da parede, das cargas permanentes e acidentais da laje e do vento. Ramalho e Corrêa (2003) explicam que a alvenaria estrutural é submetida, principalmente, a esforços de compressão, podendo existir pequenos níveis de esforços de tração, desde que estes não superem os limites de resistência à tração dos componentes da alvenaria estrutural.

No caso de as ações verticais oriundas da laje e do peso-próprio da parede atuarem em parte do comprimento do elemento estrutural, existe a tendência de as tensões se uniformizarem ao longo da altura da parede. A norma brasileira para alvenaria estrutural de Blocos Cerâmicos Projetos, NBR 15812-1 (ABNT, 2010a), prescreve que essa distribuição de tensões deve acontecer segundo um ângulo de $45^{\circ}$ nas regiões onde a estrutura é monolítica, ou seja, em paredes planas, em cantos com amarração por meio de blocos contrafiados (sem junta a prumo) e em paredes com aberturas reforçadas por vergas $\mathrm{e}$ contravergas. O reforço no contorno dessas aberturas evita o surgimento de fissuras nos cantos, devido à influência das tensões de cisalhamento geradas pelas diferentes forças de interações verticais no entorno da abertura. Em geral, as vergas na alvenaria estrutural são executadas de duas maneiras: utilizando elementos pré-moldados posicionados no vão ou a execução de vergas com o uso dos blocos-canaletas assentados sobre um gabarito de apoio, preenchidos com graute e armadura (mais usual).

Segundo Mamede (2001), as aberturas causam interrupções na elevação da alvenaria para instalação de portas e janelas, sendo responsáveis por grande parte das interferências no processo de execução das paredes e no fluxo das tensões no contorno da abertura. $\mathrm{O}$ autor menciona, ainda, que as vergas confeccionadas a partir de blocoscanaletas exigem que o operário interrompa a elevação da parede para o posicionamento do gabarito de apoio e a colocação dos blocos, da armadura e do graute, quebrando o ritmo da produção da edificação. Heineck (1991) defende a mesma ideia do efeito da continuidade das tarefas, afirma que "cada interrupção causa um desaprendizado, um retorno a um patamar de produtividade inferior" e complementa dizendo que não basta ter atividades repetitivas no canteiro, mas há a necessidade de que os operários se desloquem sem interrupção de um local de trabalho para outro e que, na execução da própria tarefa, não existam paradas devido à falta de materiais, falta de detalhamento construtivo ou interferências de outras atividades. $\mathrm{O}$ autor chega à conclusão de que o efeito de continuidade do trabalho aumenta a produtividade da mão de obra na execução da alvenaria em aproximadamente $50 \%$. Considerando a quantidade de aberturas (entre portas e janelas) que as paredes das edificações apresentam e a influência que exercem sobre a produtividade e o comportamento da alvenaria, percebe-se a necessidade de estudos específicos que considerem as diferentes alternativas tecnológicas existentes no mercado da construção civil. Nesse sentido, buscando alternativas técnicas para a melhoria da produtividade para a execução das vergas, verificou-se no mercado brasileiro a existência de um produto denominado treliças planas Murfor, cuja finalidade é atuar como reforço de paredes de alvenaria em áreas sujeitas a esforços de tração e cisalhamento. Levantamentos realizados demonstraram que há poucas informações técnicas nacionais sobre a utilização dessas treliças em substituição ao sistema convencionalmente empregado nas obras em alvenaria estrutural. Dessa forma, pretende-se neste trabalho avaliar o comportamento mecânico à flexão de duas alternativas tecnológicas para a execução de vergas, com a presença de treliças planas Murfor e grampos verticais, em comparação às comumente utilizadas nas edificações. 


\section{Uso das vergas na alvenaria estrutural}

\section{Definição}

A NBR 15812-1 (ABNT, 2010a) define verga como "viga alojada sobre a abertura de portas ou janelas, que tenha a função exclusiva de transmissão de cargas verticais para as paredes adjacentes à abertura". Mamede (2001) cita que as vergas são elementos estruturais essenciais em uma edificação, visto que evitam o surgimento de manifestações patológicas indesejáveis, como as fissuras em regiões próximo às aberturas. Tais elementos promovem a distribuição das tensões concentradas nos cantos e a absorção de tensões de tração nas aberturas. Normalmente, as vergas são executadas em concreto armado moldado no local ou pré-fabricado.

\section{Funcionamento}

Mamede (2001) realizou simulações teóricas do comportamento das aberturas em paredes de alvenaria estrutural e analisou a intensidade e o fluxo das tensões para justificar a necessidade do uso delas sobre as aberturas. Para a modelagem numérica, o autor adotou parede com dimensões de 3,60 m x 2,72 m x 0,14 m (comprimento x altura $\mathrm{x}$ largura), blocos de concreto de resistência à compressão característica de 4,5 $\mathrm{MPa}\left(f_{b k}\right)$, módulo de deformação longitudinal da alvenaria igual a 800. $f_{b k}$, ou seja, $3.600 \mathrm{MPa}$, coeficiente de Poisson igual a 0,20 , dimensões da abertura de $1,20 \mathrm{~m} \mathrm{x}$ $1,20 \mathrm{~m}$, e carregamentos distribuídos de $34 \mathrm{kN} / \mathrm{m}$. A abertura possuía verga e contraverga enrijecida com elementos pré-moldados de concreto. Como parâmetros de comparação, Mamede (2001) utilizou os seguintes valores máximos admissíveis para as tensões de cisalhamento e tensões de compressão concentradas (na parede adjacente ao vão) em alvenaria não armada, tendo como referência a norma britânica BS 5628-1 (BSI, 1992): $0,015 \mathrm{kN} / \mathrm{cm}^{2}$ e $2 . f_{m k}\left(0,036 \mathrm{kN} / \mathrm{cm}^{2}\right)$ respectivamente. Analisando os resultados das simulações, observou-se que as tensões de compressão possuem valores superiores ao adotado como máximo admissível nos cantos superiores das aberturas. $\mathrm{O}$ autor concluiu que, para a absorção dessas tensões, a presença da verga era fundamental e que seu comprimento deveria se estender além do vão da abertura. A Figura 1 mostra um exemplo típico das distribuições das tensões resultantes da análise numérica verificada por Mamede (2001).

A NBR 15812-1 (ABNT, 2010a) considera como hipótese básica para a análise das estruturas em alvenaria um comportamento elástico-linear para os materiais, mesmo para a verificação dos estados limites últimos, desde que as tensões de compressão atuantes não ultrapassem a metade do valor da resistência característica à compressão da alvenaria $\left(f_{k}\right)$. A norma cita que a dispersão das ações se dará segundo um ângulo de $45^{\circ} \mathrm{em}$ relação ao plano horizontal (Figura 2). Dessa forma, adota-se como carregamento o peso da parede contida no triângulo isósceles formado sobre o vão da abertura. Se a carga uniformemente distribuída da laje do pavimento superior ficar acima do triângulo, ela será desconsiderada. Somente o quinhão de carga, que atuar dentro dele, será computado.

A NBR 15812-1 (ABNT, 2010a) considera como hipótese básica para a análise das estruturas em alvenaria um comportamento elástico-linear para os materiais, mesmo para a verificação dos estados limites últimos, desde que as tensões de compressão atuantes não ultrapassem a metade do valor da resistência característica à compressão da alvenaria $\left(f_{k}\right)$. A norma cita que a dispersão das ações se dará segundo um ângulo de $45^{\circ}$ em relação ao plano horizontal (Figura 2). Dessa forma, adota-se como carregamento o peso da parede contida no triângulo isósceles formado sobre o vão da abertura. Se a carga uniformemente distribuída da laje do pavimento superior ficar acima do triângulo, ela será desconsiderada. Somente o quinhão de carga, que atuar dentro dele, será computado. 

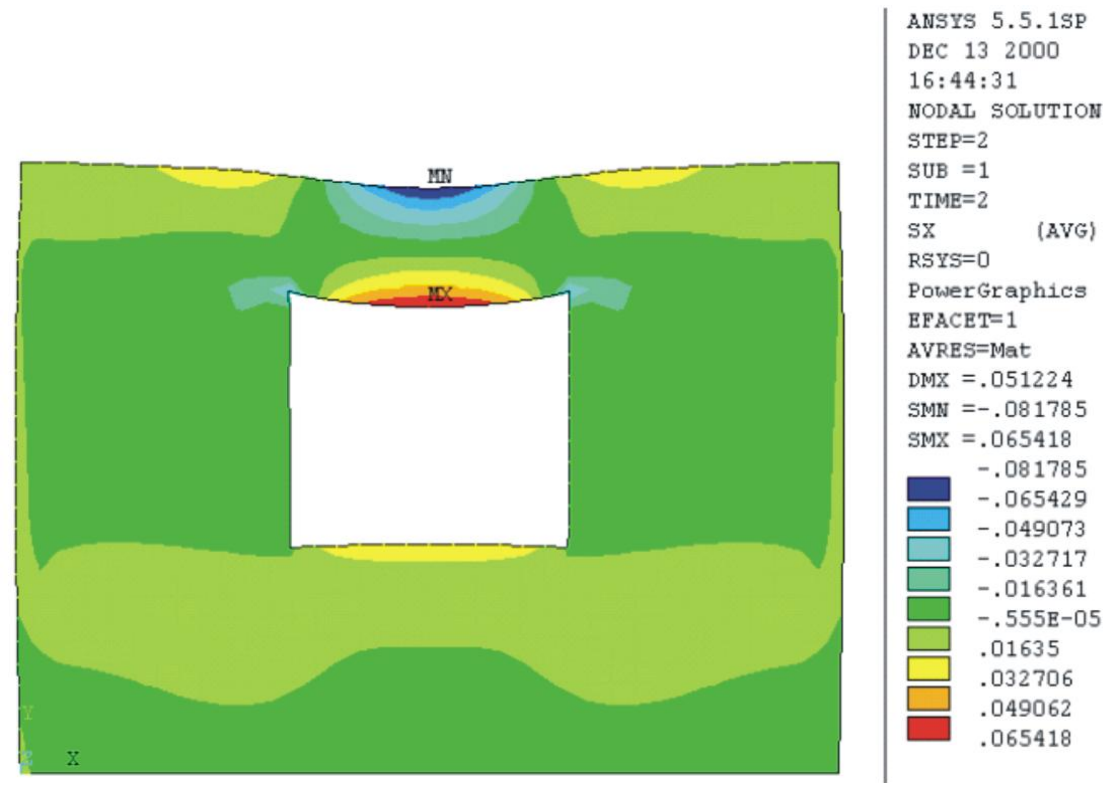

RSYS $=0$

PowerGraphics

EFACET $=1$

AVRES=Mat

DMX $=.051224$

SMN $=-.081785$

$\operatorname{SMX}=.065418$

$-.081785$

$-.065429$

$-.049073$

$-.032717$

$-.016361$

$-.555 \mathrm{E}-05$

.01635

.032706

.049062

.065418

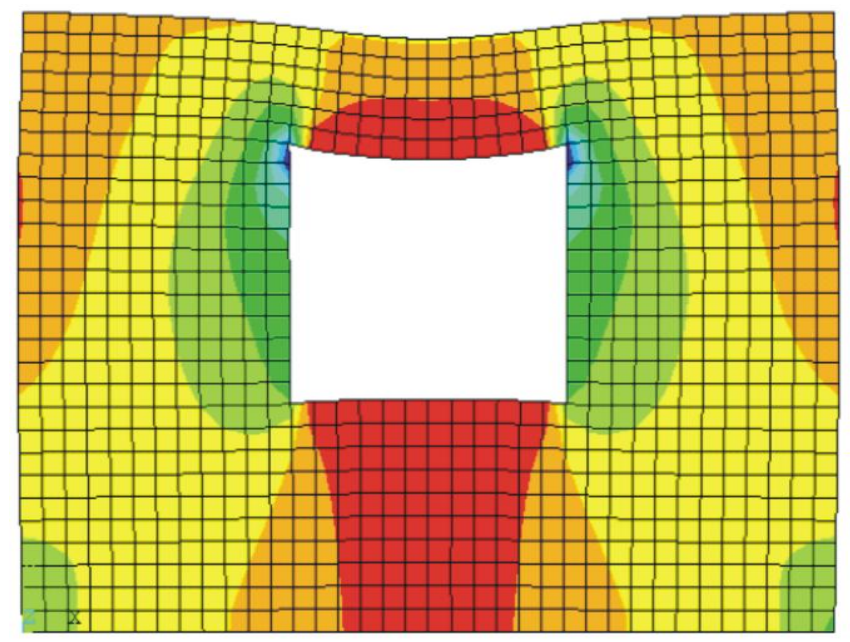

ANSYS 5.5.1SP

JAN 102001

$17: 10: 34$

NODAL SOLUTION

STEP $=2$

$\mathrm{SUB}=1$

TIME $=2$

SY

(AVG)

RSYS $=0$

PowerGraphics

EFACET $=1$

AVRES=Mat

$\mathrm{DMX}=.051224$

SMN $=-.118422$

SMX $=.002079$

$-.118422$

$-.105033$

$-.091644$

$-.078255$

$-.064866$

$-.051477$

$-.038088$

$-.024699$

$-.01131$

.002079

Figura 1 - Tensões na direção horizontal $\left(\sigma_{x}\right)$ e vertical $\left(\sigma_{y}\right)$ em $\mathrm{kN} / \mathrm{cm}^{2}$ Fonte: segundo Mamede (2001).

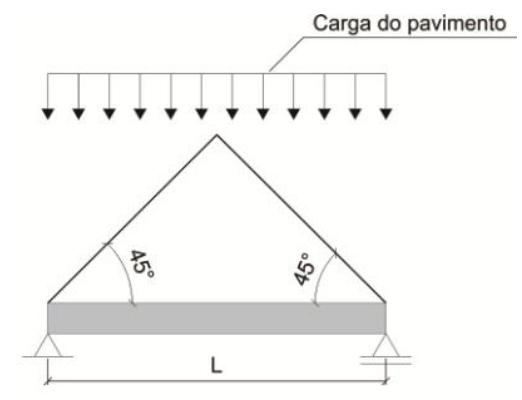

Carga distribuida fora do triângulo de carga

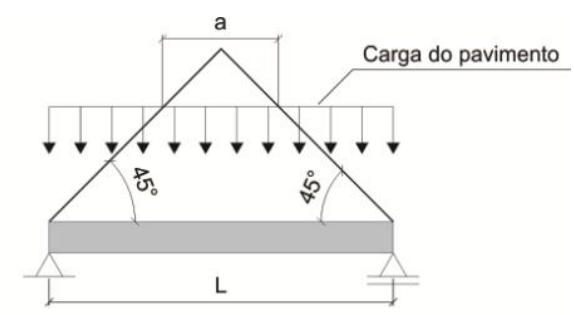

Carga distribuida dentro do triângulo de carga

Figura 2 - Distribuição das forças nos vão das aberturas em paredes de alvenaria

54 Mohamad, G.; Rezende, F. M. de; Parsekian, G. A.; Rizzatti, E.; Sánches Filho, E. de S. 
A NBR 15812-1 (ABNT, 2010a) considera como hipótese básica para a análise das estruturas em alvenaria um comportamento elástico-linear para os materiais, mesmo para a verificação dos estados limites últimos, desde que as tensões de compressão atuantes não ultrapassem a metade do valor da resistência característica à compressão da alvenaria $\left(f_{k}\right)$. A norma cita que a dispersão das ações se dará segundo um ângulo de $45^{\circ} \mathrm{em}$ relação ao plano horizontal (Figura 2). Dessa forma, adota-se como carregamento o peso da parede contida no triângulo isósceles formado sobre o vão da abertura. Se a carga uniformemente distribuída da laje do pavimento superior ficar acima do triângulo, ela será desconsiderada. Somente o quinhão de carga, que atuar dentro dele, será computado.

\section{Dimensionamento ao cisalhamento}

A NBR 15812-1 (ABNT, 2010a) considera na análise das tensões de cisalhamento da alvenaria, para os casos de paredes não armadas, que a resistência ao cisalhamento depende do traço de argamassa utilizada, da influência da aderência inicial $\left(\tau_{0}\right)$ do nível de pré-compressão $(\sigma)$ e do ângulo de atrito interno $(\mu)$, admitido como 0,5 . Essa teoria é baseada no critério de resistência de Mohr-Coulomb, conforme a Equação 1:

$\tau=\tau 0+\mu . \sigma$

Eq. 1

A parcela inicial da resistência é devida à aderência e aumenta em função do nível de précompressão (PARSEKIAN; SOARES, 2010). Por conseguinte, a NBR 15812-1 (ABNT, 2010a) recomenda valores de resistência característica ao cisalhamento da alvenaria $\left(f_{v k}\right)$ dependentes da resistência média à compressão da argamassa utilizada, descritos na Tabela 1.

Se houver armadura de flexão perpendicular ao plano de cisalhamento em furos grauteados, utilizam-se as Equações 2 e 3. Todas as unidades das equações devem ser derivadas das unidades básicas do sistema internacional.

$f_{v k}=0,35+17,5 \rho \leq 0,7 \mathrm{MPa}$

Eq. 2

$\rho=A_{s} / b . d$

Eq. 3

Caso haja carga concentrada próximo ao apoio (distância da carga ao apoio $a_{v} \leq 2 . d$ e esta corresponder a $70 \%$ ou mais do valor total da força cortante), pode-se aumentar o valor de $f_{v k}$ multiplicando-se por $2 . d a_{v}$, limitado a $0,7 \mathrm{MPa}$. Quando necessária, a armadura de cisalhamento paralela à direção de atuação da força cortante é determinada pela Equação 4.

$\frac{A_{s}}{s}=\frac{\left(V_{d-} V_{a}\right)}{0,5 . f_{y d} \cdot d} \geq 0,05 \% . b . d$

Eq. 4

Onde:

$s$ - espaçamento da armadura de cisalhamento;

$V_{d}$ - força cortante de cálculo;

$f_{v d}$ - resistência ao cisalhamento de cálculo;

$b$ - largura da seção transversal da viga;

$d$ - altura útil da viga;

$f_{y d}$ - resistência de cálculo da armadura; e

$V_{a}$ - parcela da força cortante absorvida pela alvenaria, sendo dada pela Equação 5:

$\mathrm{V}_{\mathrm{a}}=f_{v d} \cdot \mathrm{b} \cdot \mathrm{d}$

Eq. 5

Sánchez Filho (2002) analisou o dimensionamento de vigas de alvenaria estrutural submetidas à força cortante, seguindo as prescrições do Eurocode 6 (EN, 2005), e relatou que o dimensionamento baseia-se na treliça clássica de Ritter-Mörsch. A filosofia do dimensionamento segue a verificação do estado limite último, em que a força cortante solicitante de cálculo deve ser menor ou igual à força cortante resistente de cálculo, como mostra a Equação 6.

$V_{S d} \leq V_{R d}$ Eq. 6

$\mathrm{O}$ autor explica que se $V_{S d}$ for inferior à força obtida a partir da "tensão de cisalhamento resistente da alvenaria", não é necessária a adoção de armadura transversal, como indicam as Equações 7 e 8 . No entanto, para $V_{S d}>V_{R d l}$, há a necessidade de calcular uma armadura transversal para a seção.

$V_{S d} \leq V_{R d 1}$

Eq. 7

$V_{R d 1}=\frac{f_{v b} \cdot b \cdot d}{\gamma_{M}}$

Eq. 8

Onde:

$f_{v b}$ - resistência ao cisalhamento de cálculo;

$\gamma_{M}$ - coeficiente de segurança do material;

b - largura da seção transversal da viga; e

d - altura útil da viga.

Tabela 1 - Dimensões das amostras extraídas dos blocos de concreto

\begin{tabular}{c|c|c|c}
\hline & \multicolumn{2}{|c}{ Resistência média à compressão de argamassas de cimento, cal e areia (MPa) } \\
\hline \multirow{2}{*}{$f_{v k}$} & 1,5 a 3,4 & 3,5 a 7,0 & acima de 7,0 \\
\cline { 2 - 4 } & $0,10+0,5 . \sigma \leq 1,0$ & $0,15+0,5 . \sigma \leq 1,4$ & $0,35+0,5 . \sigma \leq 1,7$ \\
\hline
\end{tabular}


O parâmetro $f_{v b}$ está relacionado ao concreto de enchimento, sendo dado em função da resistência à compressão característica desse material (Tabela 2 ), onde $\mathrm{C}$ indica a classe do concreto.

Deverá ser verificada a seguinte condição para o cálculo da armadura transversal, de acordo com a Equação 9.

$V_{S d} \leq V_{R d 1}+V_{R d 2}$

Onde $V_{R d 2}$ é dado pela Equação 10 .

$V_{R d 2}=0,9 . d \cdot\left(\frac{A_{s w}}{s}\right) \frac{f_{y k}}{\gamma_{s}}(1+\operatorname{cotg} \alpha) \operatorname{sen} \alpha$ Eq. 10

Ou, ainda, considerando $a_{s w}=A_{s w} / s$, a Equação 10 pode ser escrita conforme a Equação 11.

$a_{s w}=\frac{\left(V_{S d}-V_{R d 1}\right)}{0,9 d \cdot \frac{f_{y k}}{\gamma_{S}}(1+\operatorname{cotg} \alpha) \operatorname{sen} \alpha}$

Sánchez Filho (2002) ressalta que o Eurocode 6 (EN, 2005) estabelece uma verificação do comportamento da alvenaria ao cisalhamento, para evitar a ruptura brusca da seção, por meio da Equação 12.

$V_{R d 1}+V_{R d 2} \leq \frac{0,3 \cdot f_{k} \cdot b \cdot d}{\gamma_{M}}$

Eq. 12

Onde:

$f_{k}$ - resistência à compressão da alvenaria na direção do carregamento;

$\alpha$ - ângulo de inclinação da armadura transversal;

$V_{R d l}$ - parcela de força absorvida pela alvenaria;
$V_{R d 2}$ - parcela de força absorvida pela armadura;

b - largura da seção transversal da viga; e

$\mathrm{d}$ - altura útil da viga.

Neis e Loefller (1983) citam que a ruptura por cisalhamento ocorre de maneira frágil e usualmente por tração da diagonal. O deslocamento antes da ruptura é pequeno, sem aviso prévio. Sendo assim, esse tipo de ruptura deve ser evitado. A Figura 3 mostra uma imagem de ruptura por cisalhamento e a fissura por tração na diagonal.

Suter e Keller (1976) relatam nos resultados de ensaios experimentais que o comportamento de uma viga de alvenaria armada, com seção totalmente grauteada, é semelhante ao do concreto armado. Os autores indicam que, quanto maior for a relação entre o vão e a altura da viga, menor será a resistência à força cortante, como mostra a Figura 4.

Outro aspecto importante é que o aumento da armadura de flexão também contribui para o aumento de resistência ao esforço cortante. Parsekian, Hamid e Drysdale (2012) citam que em vigas de maior vão pode ocorrer o chamado efeito arco próximo aos apoios, com a armadura de flexão funcionando como um tirante e parte dos esforços encaminhando para 0 apoio por compressão, como mostra a Figura 5.

Tabela 2 - Resistência ao cisalhamento do graute

\begin{tabular}{l|c|c|c|c}
\hline \multirow{2}{*}{ Resistência ao cisalhamento } & $\mathrm{C} 12 / \mathrm{C} 15$ & $\mathrm{C} 16 / \mathrm{C} 20$ & $\mathrm{C} 20 / \mathrm{C} 25$ & $>\mathrm{C} 25 / \mathrm{C} 30$ \\
\cline { 2 - 5 } & 0,27 & 0,33 & 0,39 & 0,45 \\
\hline
\end{tabular}

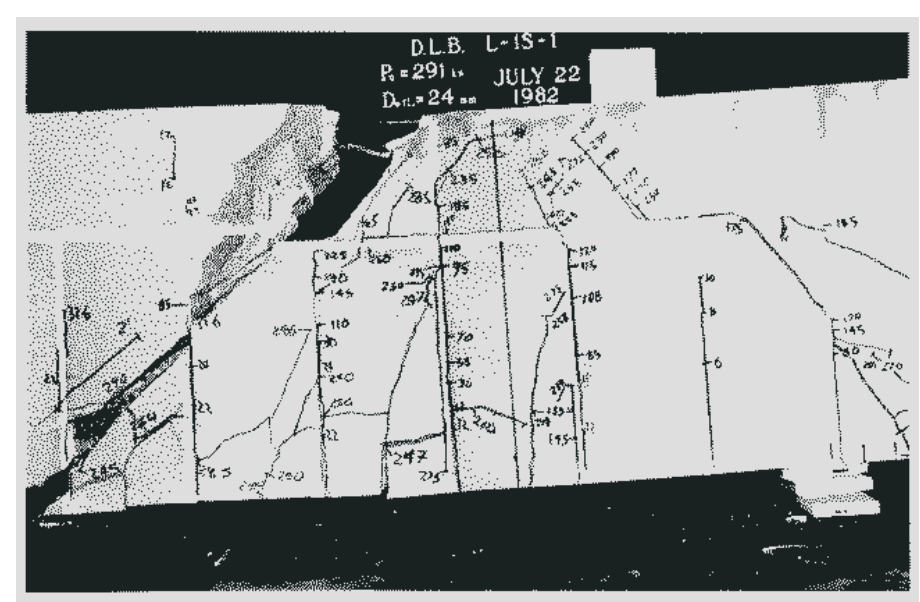

Figura 3 - Ruptura ao cisalhamento de vigas

Fonte: segundo Neis e Loeffler (1983). 


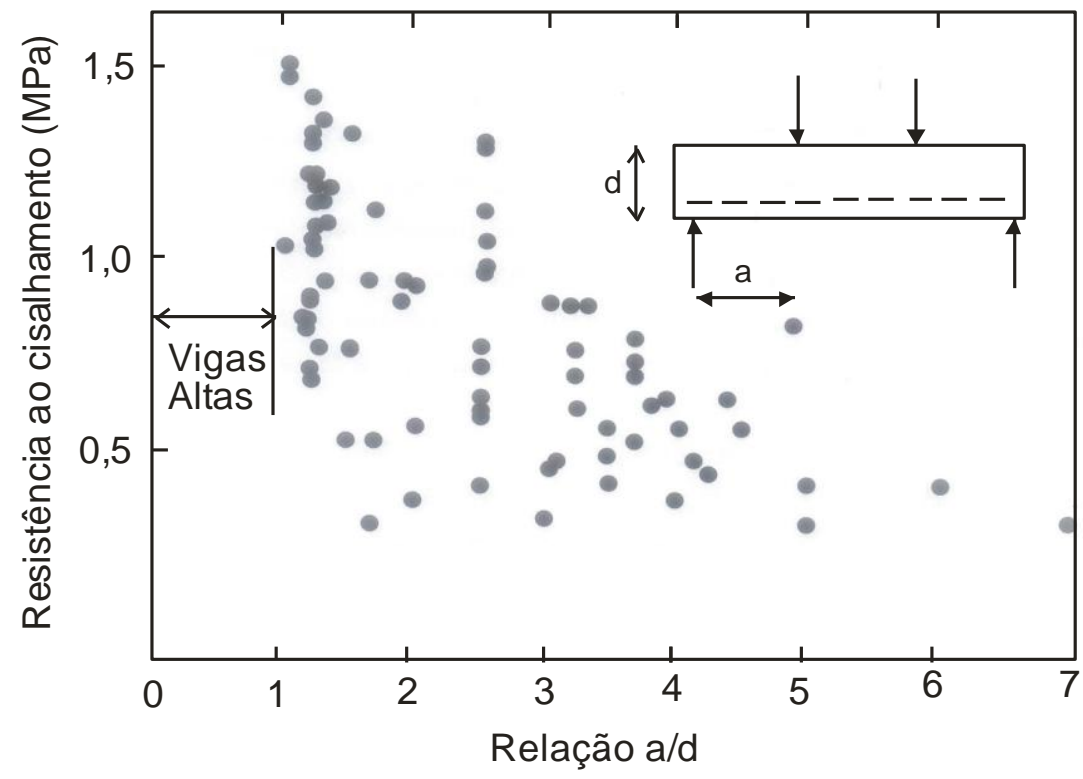

Figura 4 - Resistência ao cisalhamento em vigas em relação à a/d

Fonte: Suter e Keller (1976).

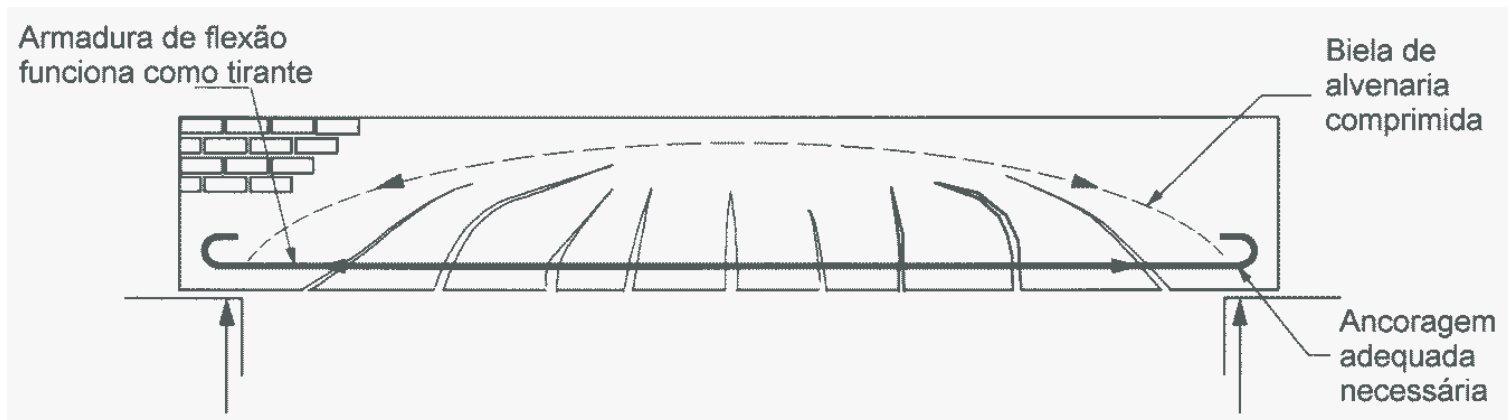

Figura 5 - Modelo de arco atirantado para vigas sem armadura transversal

Fonte: Parsekian, Hamid e Drysdale (2012).

Esse efeito foi incorporado na NBR 15961-1 (ABNT, 2011), publicada em 2011, sendo atualmente a norma brasileira mais recente para projeto de alvenaria estrutural. Para vigas biapoiadas ou em balanço, a resistência característica ao cisalhamento pode ser multiplicada pelo fator $\left.\left(2,5-0,25 . M_{\max } /\left(V_{\max } \cdot d\right)\right)\right]$, tomado sempre maior que 1,0 , desde que a resistência característica majorada não ultrapasse 1,75 MPa. Os valores de $M_{\max }$ e $V_{\max }$ correspondem, respectivamente, ao maior momento fletor e à maior força cortante no vão da viga. Portanto, a máxima força cortante será dada pela Equação 13.

$V_{d} \leq V_{a}=\left(\left(2,5-0,25 \frac{M_{\max }}{V_{\max } \cdot d}\right) \cdot(0,35+17,5 \cdot \rho)\right) \cdot \frac{b_{w} \cdot d}{2}$

Eq. 13

\section{Metodologia experimental}

A seguir é apresentada a fase experimental do trabalho, com as caracterizações dos materiais e procedimentos utilizados durante os ensaios no Laboratório de Materiais e Construção Civil (LMCC) da Universidade Federal de Santa Maria (UFSM). São descritos a execução e o ensaio até a ruptura de três tipos diferentes de modelos, construídos com blocos cerâmicos vazados e os ensaios de caracterização de seus componentes, obtendo dados para análise do comportamento mecânico das vergas.

\section{Ensaio de caracterização dos blocos}

Os blocos cerâmicos estruturais utilizados para confecção das vergas foram provenientes de uma cerâmica da região central do Rio Grande do Sul. A Figura 6 ilustra a geometria do bloco e suas dimensões. 


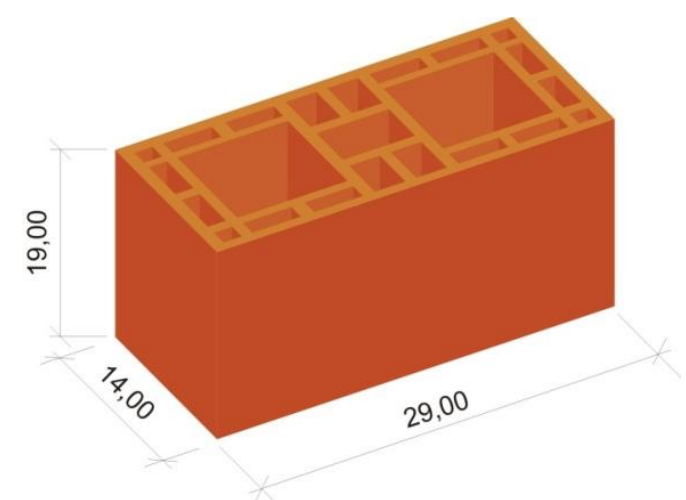

Figura 6 - Geometria do bloco cerâmico utilizado

Para determinar as características geométricas, físicas e mecânicas dos blocos, os seguintes ensaios foram realizados, conforme sugere a NBR 15270-3 (ABNT, 2005a):

(a) avaliação dos padrões dimensionais das unidades;

(b) índice de absorção de água em $24 \mathrm{~h}$;

(c) índice de absorção de água inicial (AAI);

(d) determinação da área líquida das unidades; e

(e) resistência à compressão das unidades.

As análises das características geométricas e mecânicas foram realizadas em um conjunto de 13 amostras; todos os blocos foram capeados com argamassa de cimento e areia (1:1), respeitando-se a espessura máxima de $3 \mathrm{~mm}$ em cada face. Após o período de $48 \mathrm{~h}$ de cura do capeamento, os blocos foram imersos em água fria por $24 \mathrm{~h}$. A resistência à compressão das unidades (Figura 7) foi obtida em uma prensa hidráulica da marca WPM, com capacidade máxima de carga de 300 t e uma velocidade de carregamento de $0,05 \mathrm{MPa} / \mathrm{s}$.

\section{Ensaio de caracterização das argamassas}

Para atender aos requisitos do fabricante das treliças, na construção das vergas foram utilizadas argamassas de assentamento mista de cimento, cal e areia, com traço em volume na proporção 1:0,5:4, de acordo com o recomendado pela BS 5628-1 (BSI, 1992), para garantir uma resistência à compressão da argamassa aos 28 dias de 6,0 MPa. A areia natural de rio foi empregada para a confecção das argamassas. A Tabela 3 apresenta os resultados da análise granulométrica, com as percentagens médias retidas acumuladas da areia utilizada nos experimentos. Os resultados do diâmetro máximo e módulo de finura são apresentados na Tabela 4, seguindo as recomendações da NM 248 (ASOCIACIÓN..., 2001). A Tabela 4 apresenta os resultados da massa específica, segundo a NM 52 (ASOCIACIÓN..., 2009a) e de determinação da massa unitária, segundo a NM 45 (ASOCIACIÓN..., 2006). Utilizou-se, para a composição da argamassa, cal hidratada do tipo CH II. Foram realizados ensaios de determinação da massa unitária segundo a NM 45 (ASOCIACIÓN..., 2006) e de determinação da massa específica de acordo com a NM 23 (ASOCIACIÓN..., 2000). Os resultados são apresentados na Tabela 5.

As argamassas de assentamento das vergas foram produzidas em betoneira de eixo vertical Inicialmente, fez-se a mistura da areia e cal com $50 \%$ da água estimada para o traço, ficando em repouso durante $24 \mathrm{~h}$ (para ocorrer a hidratação completa da cal), antes da adição do restante da água e do cimento. O traço em volume foi convertido em massa, baseando-se nos valores de massa unitária dos componentes, conforme indicado na Tabela 6. Para que o índice de consistência da argamassa ficasse dentro do recomendado pela NBR 13276 (ABNT, 2005b) em $260 \mathrm{~mm} \pm 5 \mathrm{~mm}$, foi adotada uma relação água/cimento igual a 1,0. A Tabela 6 traz as características da argamassa utilizada para a confecção das vergas. 


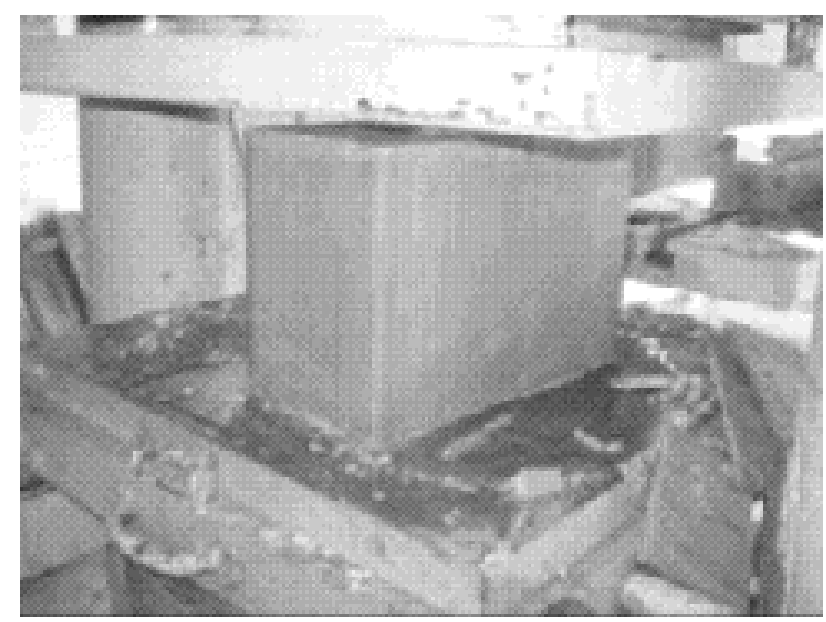

Figura 7 - Ensaio de ruptura à compressão dos blocos

Tabela 3 - Composição granulométrica da areia

\begin{tabular}{|c|c|c|c|c|c|c|c|}
\hline \multicolumn{8}{|c|}{ Composição granulométrica } \\
\hline \multicolumn{2}{|c|}{ Peneiras } & \multicolumn{2}{|c|}{ Determinção 1} & \multicolumn{2}{|c|}{ Determinação 2} & \multirow[b]{2}{*}{$\begin{array}{l}\text { \% retido } \\
\text { médio }\end{array}$} & \multirow{2}{*}{$\begin{array}{l}\% \text { retido } \\
\text { acumulado }\end{array}$} \\
\hline $\mathbf{n}^{\mathbf{o}}$ & $\mathbf{m m}$ & $\begin{array}{c}\text { Peso } \\
\text { retido (g) }\end{array}$ & $\begin{array}{c}\% \\
\text { retido }\end{array}$ & $\begin{array}{c}\text { Peso } \\
\text { retido (g) }\end{array}$ & $\%$ retido & & \\
\hline $3 / 8^{\prime \prime}$ & 9,5 & 0,00 & 0,00 & 0,00 & 0,00 & 0,00 & 0,00 \\
\hline $1 / 4 "$ & 6,3 & 0,00 & 0,00 & 0,00 & 0,00 & 0,00 & 0,00 \\
\hline 4 & 4,8 & 0,60 & 0,04 & 2,90 & 0,27 & 0,16 & 0,16 \\
\hline 8 & 2,4 & 13,50 & 0,97 & 10,30 & 0,95 & 0,96 & 1,11 \\
\hline 16 & 1,2 & 37,20 & 2,66 & 30,80 & 2,85 & 2,76 & 3,87 \\
\hline 30 & 0,6 & 191,40 & 13,69 & 159,40 & 14,75 & 14,22 & 18,09 \\
\hline 50 & 0,3 & 746,90 & 53,41 & 502,70 & 46,52 & 49,96 & 68,05 \\
\hline 100 & 0,15 & 287,70 & 20,57 & 291,50 & 26,98 & 23,77 & 91,83 \\
\hline Fundo & $<0,15$ & 121,20 & 8,67 & 83,00 & 7,68 & 8,17 & 100,00 \\
\hline \multicolumn{2}{|c|}{ Total } & $1.398,50$ & 100,00 & 1080,60 & 100,00 & 100,00 & \\
\hline
\end{tabular}

Tabela 4 - Características físicas da areia

\begin{tabular}{c|c}
\hline Módulo de finura & 1,83 \\
\hline Diâmetro máximo $(\mathrm{mm})$ & 1,20 \\
\hline Massa unitária $\left(\mathrm{g} / \mathrm{cm}^{3}\right)$ & 1,535 \\
\hline Massa específica $\left(\mathrm{g} / \mathrm{cm}^{3}\right)$ & 2,645 \\
\hline
\end{tabular}

Tabela 5 - Características físicas do cimento CP-V ARI-RS

\begin{tabular}{c|c}
\hline Massa unitária $\left(\mathrm{g} / \mathrm{cm}^{3}\right)$ & 0,637 \\
\hline Massa específica $\left(\mathrm{g} / \mathrm{cm}^{3}\right)$ & 2,319 \\
\hline
\end{tabular}

Tabela 6 - Traço em massa da argamassa de assentamento, relação água/cimento e índice de consistência adotado

\begin{tabular}{c|c|c|c}
\hline $\begin{array}{c}\text { Traço em volume } \\
\text { (cimento:cal:areia) }\end{array}$ & $\begin{array}{c}\text { Traço em massa } \\
\text { (cimento:cal:areia) }\end{array}$ & $\begin{array}{c}\text { Relação } \\
\text { água/cimento }\end{array}$ & $\begin{array}{c}\text { Índice de } \\
\text { consistência (mm) }\end{array}$ \\
\hline $1: 0,5: 4$ & $1: 0,33: 6,35$ & 1,0 & 255 \\
\hline
\end{tabular}


Foram moldados seis corpos de prova de argamassa para cada tipo de verga e armazenados no interior do LMCC, com temperatura e umidade ambiente (Figura 8a). Os ensaios foram realizados de acordo com a NBR 13279 (ABNT, 2005c). A verificação da resistência da argamassa de assentamento utilizada na produção das vergas foi obtida dos ensaios de ruptura por tração na flexão (Figura 8b) e por compressão axial (Figura 8c), de corpos de prova prismáticos de dimensões $4 \mathrm{~cm} \mathrm{x}$ $4 \mathrm{~cm} \mathrm{x} 16 \mathrm{~cm}$, rompidos aos 28 dias após a moldagem.

\section{Ensaio de caracterização dos grautes}

$O$ graute utilizado na verga seguia as recomendações da BS 5628-1 (BSI, 1992), para que a resistência à compressão atingisse aos 28 dias o mínimo de 6,5 $\mathrm{MPa}$. A areia e a cal empregadas na mistura do graute foram as mesmas utilizadas na produção das argamassas. A Tabela 7 apresenta a massa específica segundo a NM 53 (AMN, 2009b) e a massa unitária segundo a NM 45 (AMN, 2006) do pedrisco.

A produção do graute foi realizada em betoneira, com areia seca e relação água/cimento de 1,5. O traço em volume foi convertido para massa, utilizando-se os valores da massa unitária dos materiais, cuja proporção foi de 1:0,03:4,76:4,84 (cim:cal:areia:pedrisco). Para a verificação da resistência à compressão foram moldados 5 corpos de prova cilíndricos, com dimensões de $10 \mathrm{~cm} \mathrm{x}$ $20 \mathrm{~cm}$ (diâmetro e altura respectivamente), seguindo as recomendações da NBR 5738 (ABNT, 2003). O ensaio de ruptura foi baseado nas instruções da NBR 5739 (ABNT, 2007) e ocorreu após 28 dias da moldagem. Os corpos de prova foram mantidos em câmara úmida durante esse período.

\section{Ensaio de caracterização dos prismas}

Foram construídos cinco prismas com três fiadas de blocos justapostos, com juntas de argamassa com espessuras regulares de $10 \mathrm{~mm}$ de altura. Os blocos de topo e base foram capeados previamente com argamassa de cimento e areia (1:1), respeitando-se a espessura máxima de $3 \mathrm{~mm}$. Os prismas foram armazenados no interior do laboratório, com temperatura e umidade ambiente durante os 28 dias, até a realização dos ensaios de ruptura por compressão, conforme as recomendações da NBR 15812-2 (ABNT, 2010b). A Figura 9 mostra o ensaio de compressão de prismas de três fiadas.

\section{Execução das vergas}

O principal objetivo do trabalho foi analisar o comportamento mecânico de vergas constituídas de três formas distintas: um modelo, denominado $\mathrm{VL}$, foi formado por blocos contrafiados e armados com treliça plana Murfor nas duas juntas horizontais; o segundo, denominado VLT, foi formado por blocos contrafiados, armados com treliça plana Murfor nas duas juntas horizontais e com estribos do tipo grampo nas juntas verticais; o último, denominado VGL, por sua vez, possuía uma configuração diferente das anteriores (muito usual em edificações em alvenaria estrutural), formado por blocos-canaletas grauteados e armados longitudinalmente. A Figura 10 detalha os três modelos de vergas estudados.

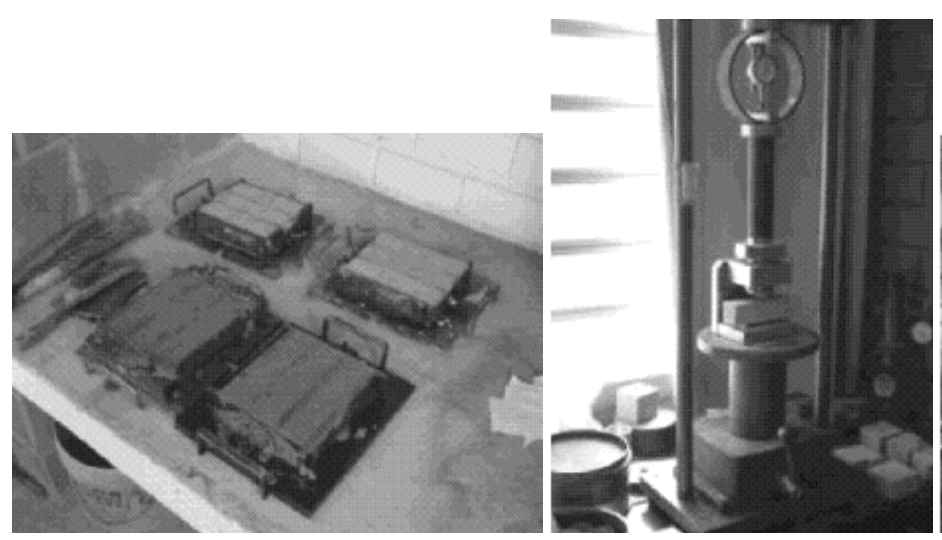

(a) (b)

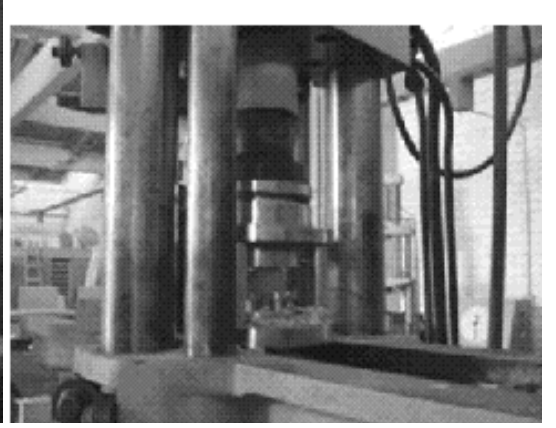

(c)

Figura 8 - Moldagem e determinação das resistências das argamassas

Tabela 7 - Características físicas do pedrisco

\begin{tabular}{c|c}
\hline Massa unitária $\left(\mathrm{g} / \mathrm{cm}^{3}\right)$ & 1,559 \\
\hline Massa específica $\left(\mathrm{g} / \mathrm{cm}^{3}\right)$ & 2,685 \\
\hline
\end{tabular}

60 Mohamad, G.; Rezende, F. M. de; Parsekian, G. A.; Rizzatti, E.; Sánches Filho, E. de S. 


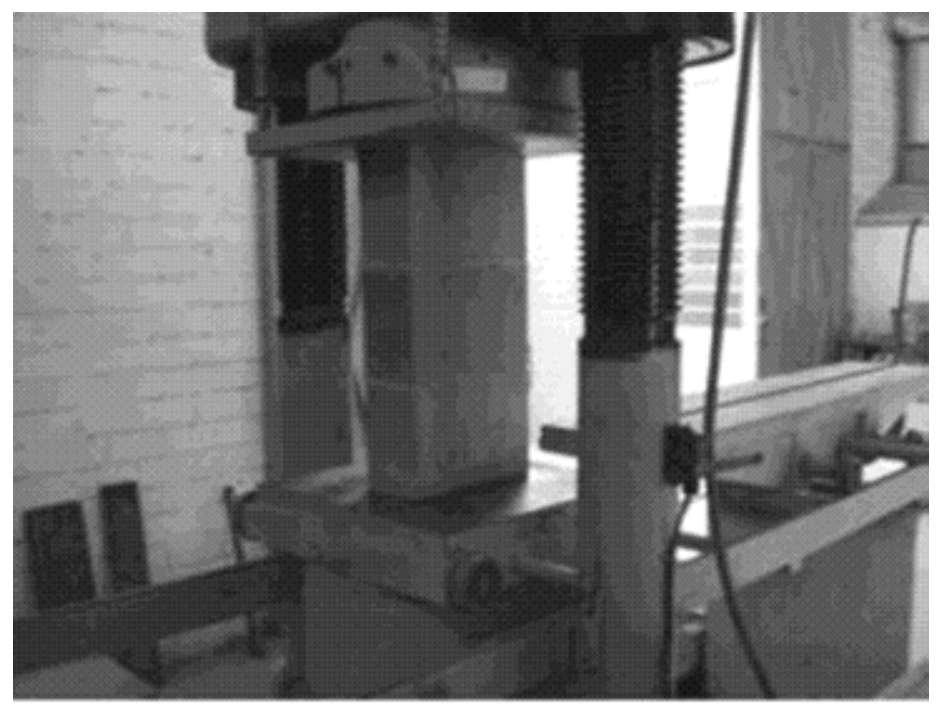

Figura 9 - Ensaio de compressão dos prismas por compressão

\section{VISTA FRONTAL}

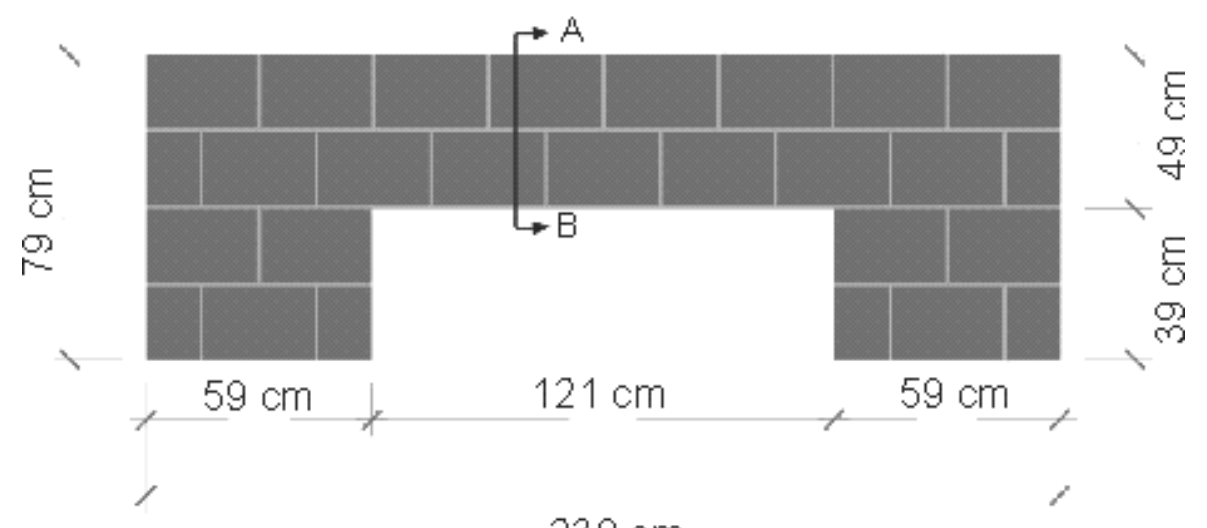

\section{$239 \mathrm{~cm}$}
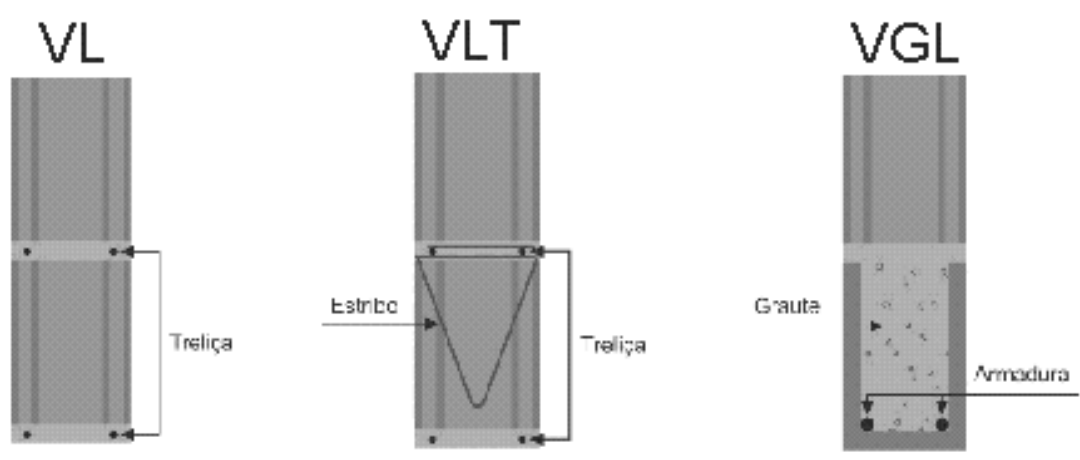

\section{CORTEAB}

Figura 10 - Vista frontal e modelos das vergas estruturais 
A treliça e o estribo utilizados nos modelos VL e VLT eram em aço galvanizado com fios de $3 \mathrm{~mm}$ e $4 \mathrm{~mm}$ de diâmetro respectivamente, cuja resistência característica de escoamento do aço foi de $f_{y k}=550 \mathrm{MPa}$. A largura da treliça foi de 11,5 $\mathrm{cm}$. Nas vergas grauteadas, a armadura longitudinal utilizada era constituída de duas barras de aço CA-50 de $8 \mathrm{~mm}$ de diâmetro. As construções das vergas foram planejadas em três etapas. Para cada modelo foram construídas 5 vergas pelo mesmo profissional. As Figuras 11 a 13 ilustram todo o processo de execução das vergas.
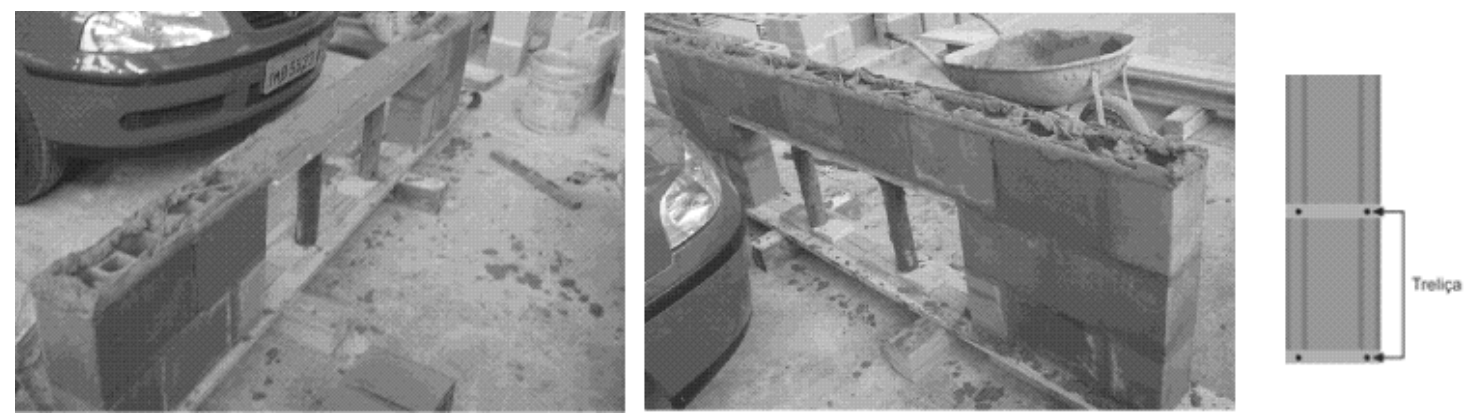

Figura 11 - Execução das vergas do modelo VL
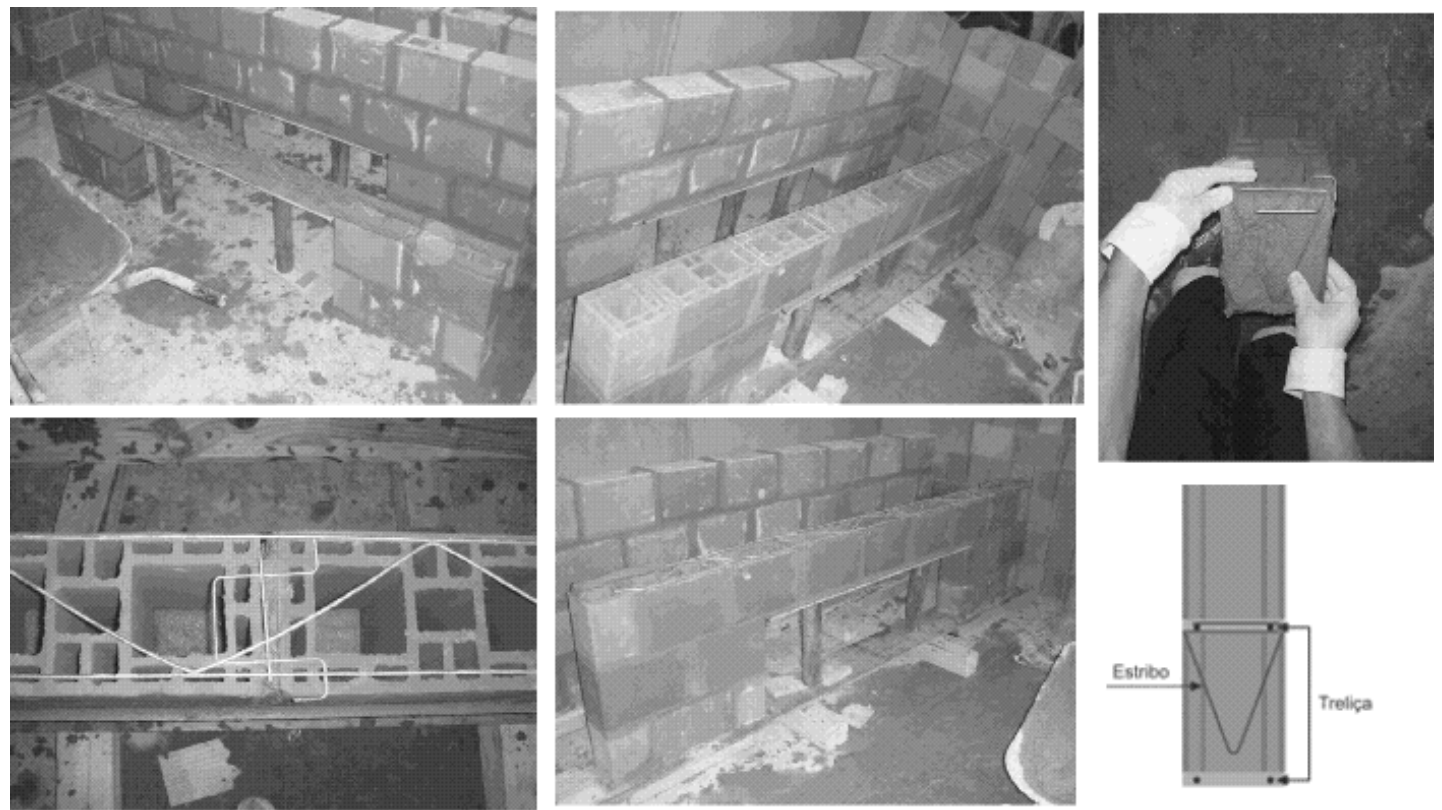

Figura 12 - Execução das vergas do modelo VLT
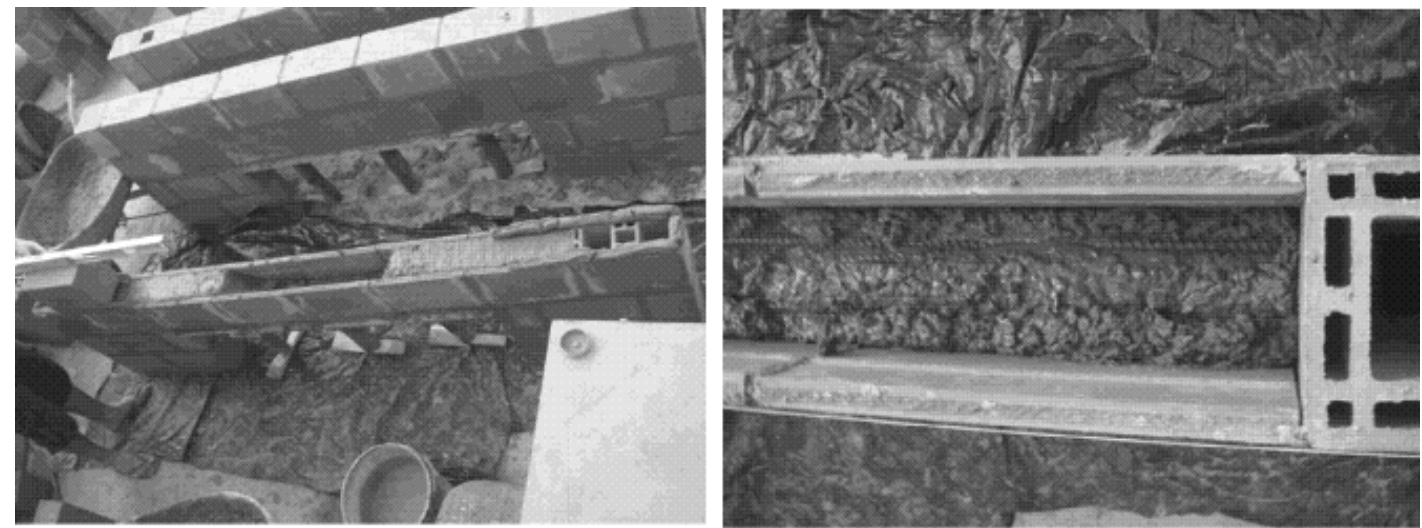

Figura 13 - Execução das vergas do modelo VGL

62 Mohamad, G.; Rezende, F. M. de; Parsekian, G. A.; Rizzatti, E.; Sánches Filho, E. de S. 
Durante esse período as mesmas ficaram armazenadas no interior do laboratório, sob a temperatura e umidade ambiente. Para a determinação da carga de ruptura, as vergas foram submetidas a carregamentos concentrados, no terço médio do vão, cuja velocidade de aplicação de força correspondeu a uma proporção de tensão aplicada de $1,0 \mathrm{MPa} / \mathrm{min}$, seguindo as recomendações da NBR 12142 (ABNT, 2010d). Os ensaios de ruptura das vergas ocorreram após 28 dias de sua construção, como descreve a norma acima citada. A Figura 14 apresenta o esquema geral do ensaio das amostras.

\section{Análise dos resultados}

A seguir são apresentados os diferentes resultados obtidos na análise experimental.

\section{Ensaios de caracterização dos materiais: blocos, argamassas e graute}

Nas Tabelas 8 a 10 são apresentados os resultados dos ensaios de caracterização geométrica, física e mecânica dos blocos cerâmicos utilizados para a confecção dos prismas e vergas. Observa-se na
Tabela 8 uma aceitável variação dimensional nos blocos amostrados, segundo recomendações da NBR 15270-2 (ABNT, 2005d), que define como limites máximos o intervalo de $\pm 3 \mathrm{~mm}$ para as dimensões médias em relação às medidas nominais.

O valor da absorção de água em 24 h obtidos nos ensaios ficou dentro dos limites dos valores recomendados pela NBR 15270-2 (ABNT, 2005d), de $8 \%$ a $22 \%$. Em relação ao índice de absorção de água inicial (AAI), a NBR 15270-3 (ABNT, 2005a) sugere que os blocos cerâmicos com taxa de absorção superiores a $\left(30 \mathrm{~g} / 193,55 \mathrm{~cm}^{2}\right) / \mathrm{min}$ necessitam ser umedecidos antes do assentamento. Dessa forma, de acordo com os resultados mostrados na Tabela 9, pode-se concluir que não existe a necessidade da molhagem dos blocos antes do assentamento, pois os valores ficaram abaixo do limite estabelecido na NBR 15270-3 (ABNT, 2005a).

Na Tabela 10 são apresentados os resultados médios de resistência à compressão dos blocos, argamassas, grautes e prismas, com seus respectivos valores estatísticos.
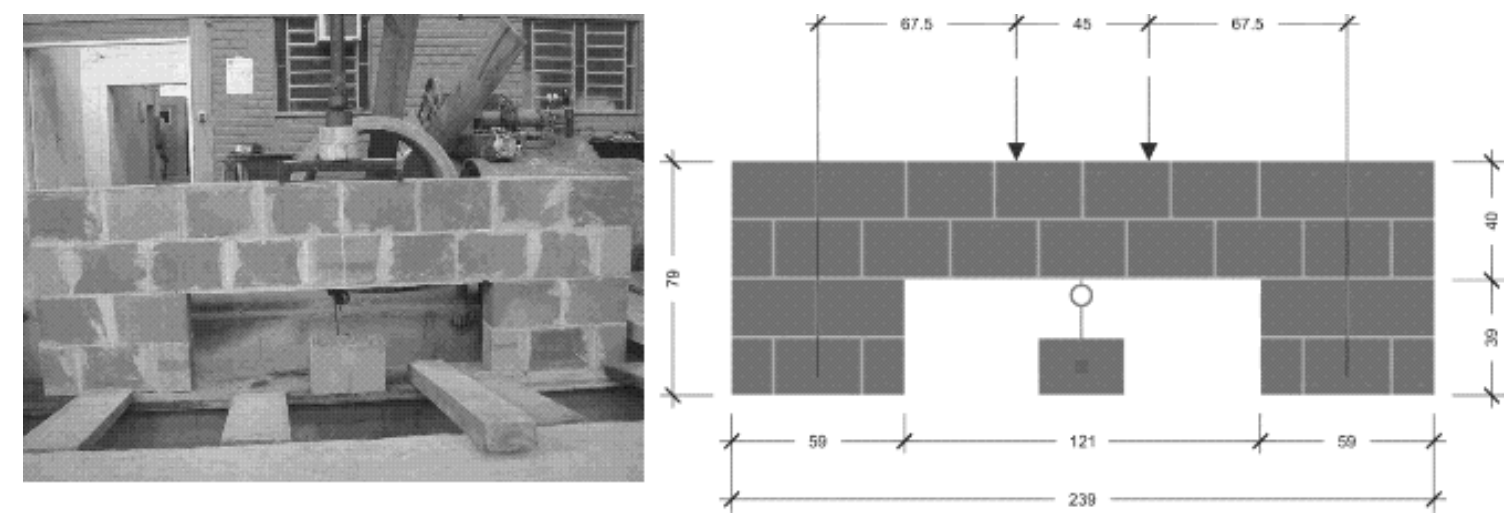

Figura 14 - Esquema geral do ensaio das vergas

Tabela 8 - Características geométricas dos blocos cerâmicos vazados

\begin{tabular}{c|c|c|c}
\hline & Largura (mm) & Altura (mm) & Comprimento (mm) \\
\hline Dimensão nominal & 140,0 & 190,0 & 290,0 \\
Dimensão real média & 140,9 & 191,3 & 288,8 \\
Desvio padrão (s.d) & 0,1 & 0,9 & 0,5 \\
Coeficiente de variação (\%) & 0,07 & 0,48 & 0,19 \\
\hline
\end{tabular}

Tabela 9 - Características físicas dos blocos cerâmicos vazados

\begin{tabular}{|c|c|c|c|c|}
\hline & $\begin{array}{c}\text { Área líquida } \\
\left(\mathrm{cm}^{2}\right)\end{array}$ & $\begin{array}{l}\text { Área bruta } \\
\qquad\left(\mathrm{cm}^{2}\right)\end{array}$ & $\begin{array}{c}\text { Índice de } \\
\text { absorção } 24 \\
\text { h (\%) }\end{array}$ & $\begin{array}{c}\text { Índice de absorção } \\
\text { inicial } \\
\left(\mathrm{g} / 193,55 \cdot \mathrm{cm}^{2}\right) / \mathrm{min}\end{array}$ \\
\hline $\begin{array}{c}\text { Média } \\
\text { Desvio padrão (s.d) } \\
\text { Coeficiente de variação }(\%)\end{array}$ & $\begin{array}{c}155,0 \\
0,7 \\
0,44\end{array}$ & $\begin{array}{c}406,4 \\
0,8 \\
0,19\end{array}$ & $\begin{array}{c}9,84 \\
0,3 \\
3,04\end{array}$ & $\begin{array}{c}26,2 \\
6,1 \\
23,21\end{array}$ \\
\hline
\end{tabular}

Análise do emprego de armaduras treliçadas planas como alternativa tecnológica para a execução de vergas em 63 alvenaria estrutural 
Tabela 10 - Características mecânicas dos blocos cerâmicos vazados

\begin{tabular}{|c|c|c|c|c|c|c|}
\hline & \multicolumn{2}{|c|}{ Bloco } & \multicolumn{2}{|c|}{ Argamassa } & \multirow{2}{*}{$\begin{array}{l}\text { Graute } \\
f_{\text {graute }} \\
\text { (MPa) }\end{array}$} & \multirow{2}{*}{$\begin{array}{r}\text { Prisma } \\
f_{\text {prisma }} \\
\text { (MPa) }\end{array}$} \\
\hline & $\begin{array}{l}f_{b} \text { Área } \\
\text { líquida } \\
(\mathrm{MPa})\end{array}$ & $\begin{array}{c}f_{b} \text { Área bruta } \\
\text { (MPa) }\end{array}$ & $\begin{array}{c}f_{\text {arg. }} \\
\text { (MPa) }\end{array}$ & $\begin{array}{c}f_{\text {arg. flexão }} \\
\text { (MPa) }\end{array}$ & & \\
\hline \multirow{3}{*}{$\begin{array}{c}\text { Média } \\
\text { Desvio padrão (s.d) } \\
\text { Coeficiente de variação }(\%)\end{array}$} & 26,24 & 10,01 & 6,47 & 2,42 & 6,94 & 4,23 \\
\hline & 3,64 & 1,39 & 1,13 & 0,42 & 0,72 & 0,74 \\
\hline & \multicolumn{2}{|c|}{13,87} & 17,49 & 16,51 & 10,33 & 17,52 \\
\hline
\end{tabular}

Nota: Legenda:

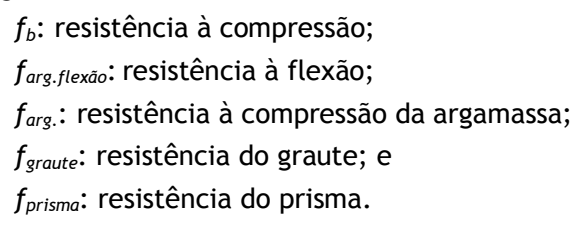

\section{Resultados dos ensaios de ruptura das vergas estruturais e as análises estatísticas}

A seguir são apresentados os resultados dos experimentos realizados, o modo de ruptura e a análise estatística.

\section{Força última de ruptura das vergas estruturais}

Os resultados dos ensaios das forças últimas de ruptura dos diferentes modelos estruturais de vergas são apresentados na Tabela 11, juntamente com a média, o desvio padrão e o coeficiente de variação. Pelos resultados experimentais das forças últimas de ruptura, observa-se que o uso das treliças nas juntas de assentamento nas duas fiadas, modelo VL, resultou em menores resistências. O uso combinado de treliças e estribos, modelo VLT, aumentou a capacidade resistente das vergas em $57 \%$ em relação ao modelo VL. A diferença na capacidade de suporte entre a verga grauteada VGL foi $85,6 \%$ maior que o modelo VLT e $192,6 \%$ maior que o modelo VL. O modelo de verga grauteada é consagrado no sistema construtivo em alvenaria estrutural, mas sua utilização reduz a produtividade na execução de paredes com aberturas, principalmente em obras de grande porte e com número elevado de aberturas como portas e janelas. Dessa forma, a inserção de armaduras nas juntas de assentamento configura uma alternativa racionalizada quando a edificação possui aberturas pequenas (menores que 1,20 m) e sem incidência de carregamentos elevados sobre as lajes.

\section{Modo de ruptura das vergas estruturais}

Os modos de rupturas das vergas foram muito semelhantes. Nos modelos VL1, VL2 e VL4, além das fissuras verticais nos blocos próximos a um dos pontos de aplicação da força, ocorreu o destacamento da interface bloco e junta, de maneira inclinada na direção do canto esquerdo do vão. No modelo VL3 foram observadas fissurações na diagonal, na interface bloco e junta de argamassa. No modelo VL5, além do esmagamento do bloco sob a aplicação de uma das forças, ocorreu o destacamento da interface bloco e junta, de maneira inclinada, em direção a ambos os cantos do vão. Em nenhum dos referidos modelos foram observadas fissuras no meio do vão provocado pela flexão. A Figura 15 ilustra os modos de ruptura das vergas do tipo VL.

Nos modelos de vergas VLT1 e VLT2 ocorreram fissuras diagonais nos blocos próximos a um dos pontos de aplicação da força, provocando um destacamento da interface bloco e junta de assentamento. Nos modelos VLT3, VLT4 e VLT5 ocorreram modos de ruptura idênticos, com esmagamento do bloco sob a aplicação de uma das forças e fissurações diagonais em blocos e juntas na direção do canto esquerdo do vão. Em nenhum dos referidos modelos foram observadas fissuras no meio vão. A Figura 16 ilustra os modos de ruptura das vergas do tipo VLT. 
Tabela 11 - Resultados dos experimentos em vergas

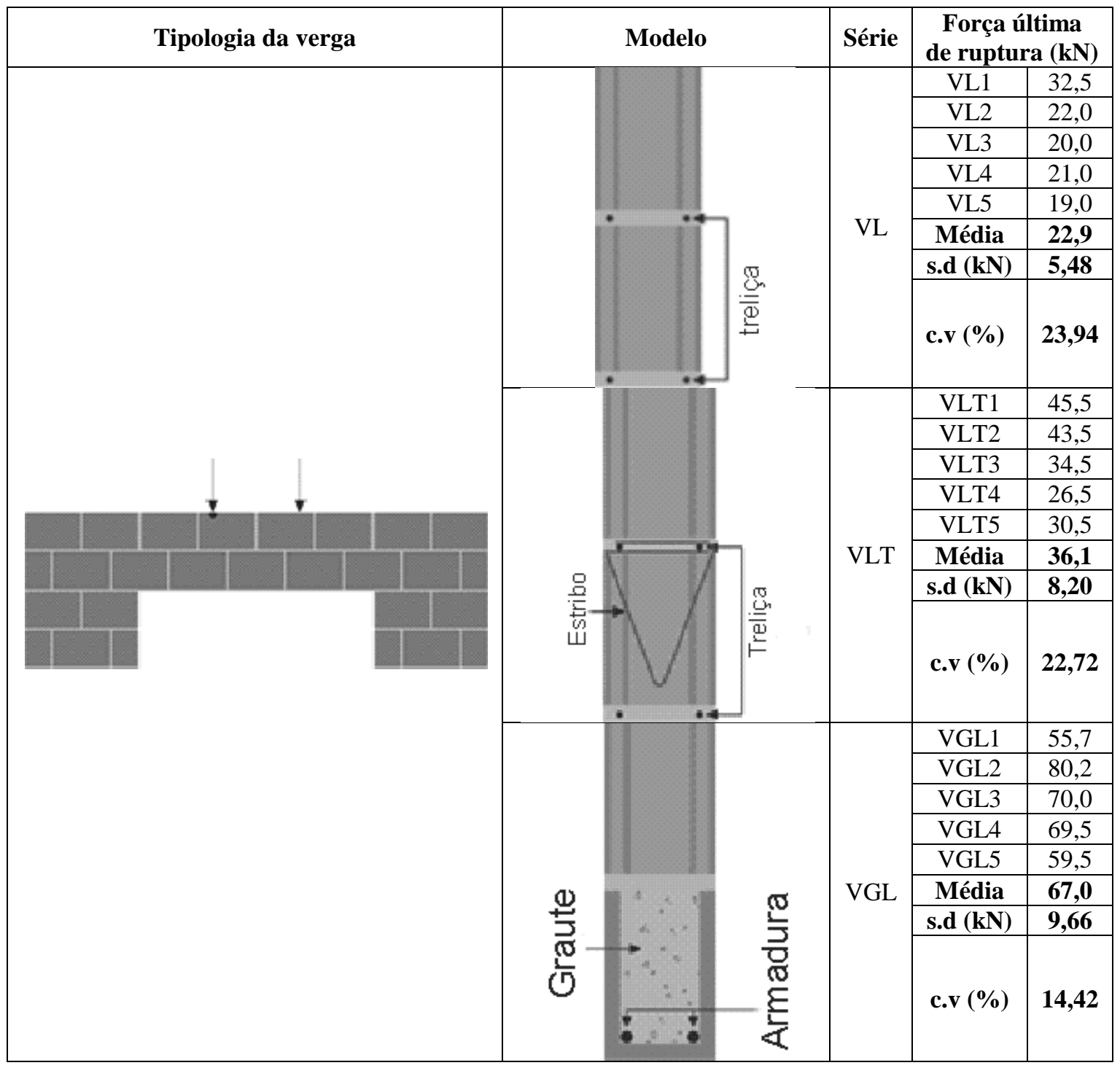




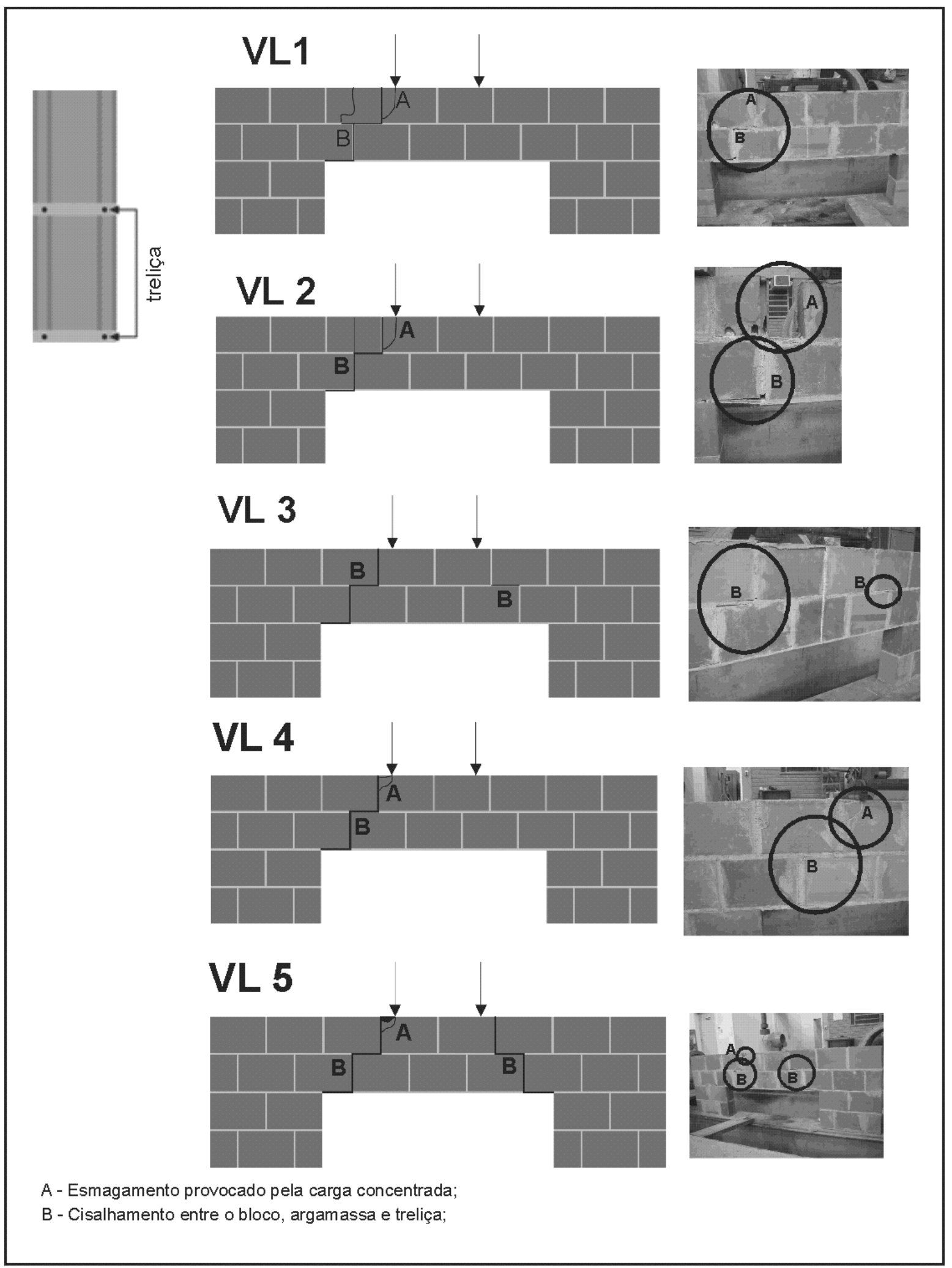

Figura 15 - Modo de ruptura das vergas, modelo VL 


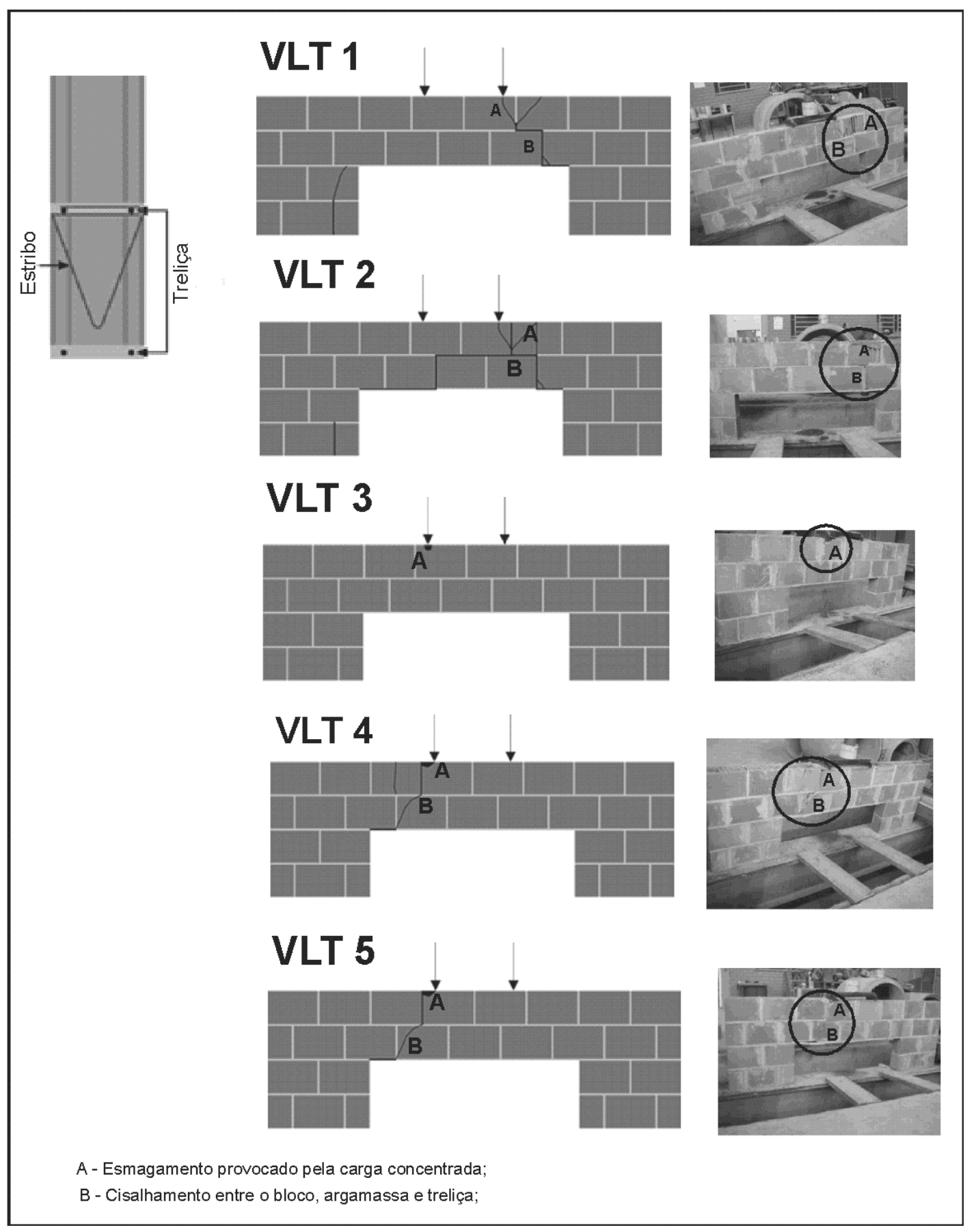

Figura 16 - Modo de ruptura das vergas, modelo VLT

O modo de ruptura da verga VGL1 ocorreu de forma localizada, junto aos pontos de aplicação da força concentrada, não alcançando o nível de fissuração visível, em virtude da maior rigidez da verga com o graute. Por conseguinte, no modelo VGL2, o bloco sob um dos pontos de aplicação da força foi esmagado e manifestou fissuras verticais nas paredes externas. Nos modelos de vergas VGL3 e VGL4, além das fissuras verticais nos blocos próximos a um dos pontos de aplicação da força, ocorreu o destacamento da interface bloco e junta, com fissurações no graute na forma diagonal, em direção ao canto esquerdo do vão. No modelo de verga VGL3 observou-se, ainda, o surgimento de fissuras verticais nos blocos da base da verga e horizontais no graute. $\mathrm{O}$ modelo de verga VGL5 apresentou ruptura localizada do bloco junto a um dos pontos de aplicação da força concentrada e fissuras horizontais no graute. A Figura 17 ilustra os modos de ruptura das vergas do tipo VGL. 


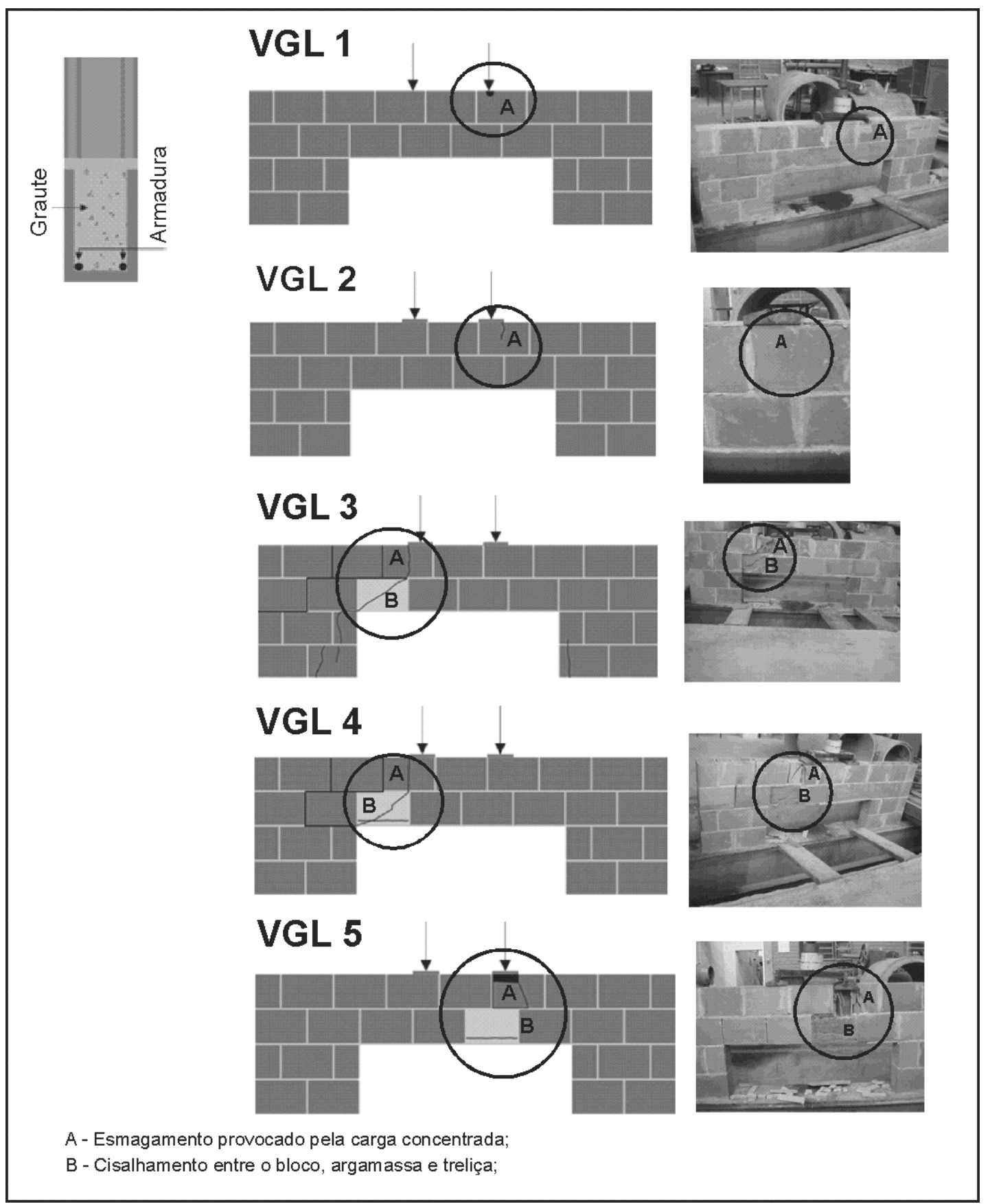

Figura 17 - Modo de ruptura das vergas, modelo VGL

\section{Análise estatística das diferenças entre os modelos de vergas}

Para analisar a diferença das capacidades de suporte dos modelos de vergas foi realizada uma comparação entre as médias das forças, por meio de testes estatísticos, aplicando-se a análise de variância (ANOVA) e o teste de Duncan. Segundo Prudêncio Júnior (1986), quando é feita uma comparação entre as médias das amostras, existe um erro embutido, por se tratar de variáveis aleatórias. Então, é correto levar em consideração a variabilidade dos dados que geraram cada média e estabelecer níveis de confiabilidade para poder concluir se existe ou não diferença significativa entre os valores médios em questão. Para Costa Neto (1977), a análise de variância (ANOVA) é um método suficientemente poderoso para poder identificar diferenças entre as médias. Segundo Fonseca e Martins (1982), esse método indica a aceitação ou rejeição da hipótese de igualdade das médias. Se a hipótese de igualdade for rejeitada, admite-se que pelo menos uma das médias seja diferente das demais. No entanto, a ANOVA não

68 Mohamad, G.; Rezende, F. M. de; Parsekian, G. A.; Rizzatti, E.; Sánches Filho, E. de S. 
indica quais médias são diferentes das demais. Para isso, existem alguns testes estatísticos que solucionam essa questão, como cita Oliveira (2008). A aplicação da ANOVA tem por base a distribuição $F$ de Snedecor e será empregada para o caso de um fator com $k$ níveis fixos. Nesse caso, com a hipótese da Equação 12, verifica-se se as várias médias populacionais são iguais ou se pelo menos uma é diferente. Por isso, verifica-se como se comporta a variação entre as médias das populações e a variação dentro dessas populações.

$H_{0}: \mu_{1}=\mu_{2}=\cdots=\mu_{k}$

Eq. 12

Sabe-se que, para cada série houve 5 repetições, é possível realizar a análise de variância e concluir se existe ou não diferença significativa entre as médias. A Tabela 12 traz os valores obtidos com a aplicação da ANOVA, para um nível de confiabilidade de $95 \%$.

Como $\mathrm{F}_{\text {calc }}>\mathrm{F}_{\alpha}(2,12)$, a hipótese $\mathrm{H}_{0}$ pode ser rejeitada, ou seja, existe diferença significativa de pelo menos uma das médias. Para se determinar qual ou quais médias possuem diferenças significativas, utilizou-se o teste de Duncan. O teste de Duncan, assim como o teste de Tukey, baseia-se na amplitude total studentized range, para o cálculo de diversas diferenças mínimas significantes. Para aplicar o teste de Duncan, as médias devem ser ordenadas de forma crescente, para posteriormente calcular a diferença mínima significante (d.m.s.) e comparar a maior média com a menor. No conjunto ordenado das médias, a comparação entre a maior e a menor média corresponde a um intervalo que abrange todas as $k$ médias. Se a diferença entre a maior e a menor média é significante, calcula-se outra diferença mínima, agora para comparar as médias em um intervalo abrangendo $\mathrm{k}-1$.

Para o teste de Duncan, deve ser determinado o desvio padrão das médias (Equação 13):

$S_{x}=\frac{S}{\sqrt{n_{h}}}$

Sendo (Equação 14):

$S=\sqrt{M Q R}$

Onde:

MQR é a média dos quadrados dos resíduos;

$\mathrm{n}_{\mathrm{h}}$ é a média harmônica entre os $\mathrm{n}_{\mathrm{i}}$;

$\mathrm{n}_{\mathrm{i}}$ é o número de elementos de cada grupo; e

k é o número de grupos.

Portanto (Equação 15): $\frac{1}{n_{h}}=\frac{\sum \frac{1}{n_{i}}}{k}$

Eq. 15

O que produz o seguinte resultado (Equação 16):

$\frac{1}{n_{h}}=\frac{\sum \frac{1}{n_{i}}}{k}=\frac{\frac{1}{5}+\frac{1}{5}+\frac{1}{5}}{3}=\frac{0,6}{3}=0,20$

Eq. 16

e (Equação 17):

$S_{x}=\frac{S}{\sqrt{n_{h}}}=\frac{7,97}{\sqrt{5}}=3,56$

Para a determinação das diferenças mínimas significativas entre as médias, utiliza-se a equação $R_{k}=S_{x} \cdot r_{k}$, onde: $\mathrm{r}_{\mathrm{k}}$ é o índice dado pela tabela studentized range, que depende dos graus de liberdade de $S_{\mathrm{x}}$ e do nível de significância (adotado como 0,05), como mostra a Tabela 13.

A Tabela 14 apresenta a comparação das diferenças entre as médias ordenadas com os valores de $\mathrm{R}_{\mathrm{k}}$. As comparações são realizadas em função das diferenças entre as médias ordenadas com os valores de $R_{k}$. Se a diferença entre as médias de força das vergas for maior que o correspondente comparativo, a diferença é declarada significativa. Caso contrário, é declarada não significativa. Como pode ser verificado na Tabela 14, existem diferenças significativas entre os valores de força máxima de ruptura das vergas, quando comparado entre os modelos de vergas, ou seja, quando comparado verga grauteada com verga com a treliça plana (VGL - VL); entre a verga grauteada e a verga com treliça plana e grampos verticais (VGL - VLT); e entre vergas com treliças planas e grampos verticais com vergas somente com treliça plana (VLT - VL).

\section{Comparação entre o valor teórico do esforço cortante último em relação à NBR 15812-1 (ABNT, 2010) e o Eurocode 6 (EN, 2005)}

As normas NBR 15812-1 (ABNT, 2010a) e Eurocode 6 (EN, 2005) fornecem orientações para o dimensionamento de elementos submetidos ao esforço cortante. Com o intuito de verificar se os valores obtidos experimentalmente são compatíveis com os recomendados pelas normalizações, foi aplicada a formulação descrita nas normalizações e comparados os valores com os resultados experimentais. A Tabela 15 resume as características das vergas necessárias para a análise. 
Tabela 12 - Análise das variâncias das forças máximas de ruptura das vergas

\begin{tabular}{c|c|c|c|c|c}
\hline Fonte da variação & SQ & GDL & QM & $\mathbf{F}_{\text {calc }}$ & \multirow{2}{*}{$\mathbf{F}_{\boldsymbol{\alpha}(\mathbf{2}, \mathbf{1 2})}$} \\
\hline Entre grupos & 5123,10 & $\mathrm{k}-1=2$ & 2561,55 & \multirow{2}{*}{40,29} & \multirow{2}{*}{3,89} \\
\hline Dentro dos grupos & 763,03 & $\mathrm{n}-\mathrm{k}=12$ & 63,59 & & \\
\hline Total & 5886,13 & 14 & 420,44 & & \\
\hline
\end{tabular}

Nota: Legenda:

GDL são os graus de liberdade;

$\mathrm{n}$ é o número de amostras;

k é o número de populações;

SQ é a soma dos quadrados;

QM é o quadrado das médias;

$\mathrm{F}_{\mathrm{cal}}$ é a razão $\mathrm{F}$, que indica o tamanho da diferença entre as amostras, em função do tamanho da variação dentro de cada amostra.

Tabela 13 - Valores de $\mathbf{r}_{\mathbf{k}} \mathbf{e} \mathbf{R}_{\mathbf{k}}$

\begin{tabular}{c|c|c}
\hline & \multicolumn{2}{|c}{ GDL $=\mathbf{n}-\mathbf{k}=\mathbf{1 2}$} \\
\hline Número de grupos & $\mathbf{2}$ & $\mathbf{3}$ \\
\hline $\mathrm{r}_{\mathrm{k}}$ & 3,081 & 3,770 \\
$\mathrm{R}_{\mathrm{k}}$ & 10,99 & 13,44 \\
\hline
\end{tabular}

Tabela 14 - Resultados da aplicação do método de Duncan

\begin{tabular}{c|c|c|c}
\hline Vergas & Diferença entre as médias & Comparações & Conclusão \\
\hline VGL - VL & 44,1 & 13,44 & Existe diferença significativa \\
VGL - VLT & 30,90 & 10,99 & Existe diferença significativa \\
VLT - VL & 13,20 & 10,99 & Existe diferença significativa \\
\hline
\end{tabular}

Tabela 15 - Características físicas e mecânicas dos modelos em análise

\begin{tabular}{l|c|c|c}
\hline \multicolumn{1}{c|}{ Característica } & VL & VLT & VGL \\
\hline Seção transversal $\left(\mathrm{cm}^{2}\right)$ & 560 & 560 & 210 \\
Largura da seção $-\mathrm{b}(\mathrm{cm})$ & 14 & 14 & 14 \\
Altura útil - d $(\mathrm{cm})$ & 40 & 40 & 15 \\
Distância da carga concentrada ao apoio $-\mathrm{a}_{\mathrm{v}}(\mathrm{cm})$ & 38 & 38 & 38 \\
Relação entre: $2 \mathrm{~d} / \mathrm{a}_{\mathrm{v}}$ & 2,11 & 2,11 & 2,00 \\
Armadura de flexão $-\mathrm{A}_{\mathrm{s}}\left(\mathrm{mm}^{2}\right)$ & 50,00 & 50,00 & 100,50 \\
Armadura de cortante $-\mathrm{A}_{\mathrm{sw}}\left(\mathrm{mm}^{2} / \mathrm{m}\right), \alpha=90^{\circ}, \mathrm{s}=30 \mathrm{~cm}, f_{y k}=550 \mathrm{MPa}$ & 0,00 & 47,12 & 0,00 \\
Taxa geométrica da armadura de flexão $-\rho(\%)$ & 0,089 & 0,089 & 0,180 \\
Força média de ruptura dos ensaios em vergas $(\mathrm{kN})$ & 22,90 & 36,10 & 67,00 \\
Força cortante última nos apoios $-V_{u}(\mathrm{kN})$ & 11,45 & 18,05 & 33,50 \\
\hline
\end{tabular}

A partir dos parâmetros acima elencados foi verificado o valor da força cortante máxima teórica, seguindo as recomendações da NBR 15812-1 (ABNT, 2010) para as cargas concentradas próximas ao apoio, onde $f_{v k}=0,35+17,5 . \rho(\%)$. A Tabela 16 sintetiza os resultados das equações. Também está incluída nessa tabela a previsão de carga máxima, de acordo com a NBR 15961-1 (ABNT, 2011), que trata a questão da carga próxima ao apoio, de maneira distinta à NBR 15812-1 (ABNT, 2010a). Conforme se pode observar, os valores previstos em ambas às normas são próximos.
O Eurocode 6 (EN, 2005) sugere uma relação entre a resistência característica ao cisalhamento da alvenaria com a resistência à compressão do graute. Como a classe de resistência do graute utilizado no estudo experimental foi inferior aos valores tabelados, adotou-se um valor de resistência ao cisalhamento proporcional de 0,20 $\mathrm{Mpa}$, o que reduz naturalmente a resistência ao cisalhamento da alvenaria. A Tabela 17 sintetiza os resultados das equações.

Observa-se pelos resultados das Tabelas 16 e 17 que o esforço cortante máximo resistido pela alvenaria, segundo as prescrições normativas NBR 15812-1

70 Mohamad, G.; Rezende, F. M. de; Parsekian, G. A.; Rizzatti, E.; Sánches Filho, E. de S. 
(ABNT, 2010a) e Eurocode 6 (EN, 2005) foram diferentes. A metodologia sugerida pelo Eurocode 6 (EN, 2005) relaciona a resistência característica ao cisalhamento da alvenaria com a resistência à compressão do graute. Por meio do estudo comparativo do dimensionamento de vergas ao cisalhamento, utilizando-se as prescrições propostas pelo código europeu e pelo brasileiro, observou-se que a metodologia europeia resultou em valores mais conservadores para o esforço cortante resistente. $\mathrm{O}$ valor do esforço cortante teórico último para as vergas do tipo VGL, calculado a partir das recomendações da NBR 15812-1 (ABNT, 2010a), foi inferior à força cortante média de ruptura dos modelos ensaiados.

\section{Conclusões}

De acordo com os resultados pode-se concluir que:

(a) houve um aumento na resistência ao cisalhamento do modelo VLT em relação ao modelo VL de 57\%, o que confirma que a inserção da armadura de grampo nas juntas verticais melhorou o desempenho da verga. A eficiência do modelo convencional grauteado foi significativamente maior em comparação com os modelos VLT e VL. A diferença na capacidade de suporte entre a grauteada VGL foi $85,6 \%$ maior que o modelo VLT e $192,6 \%$ maior que o modelo VL;

(b) as vergas grauteadas são consagradas no sistema construtivo em alvenaria estrutural, mas sua utilização reduz a produtividade na execução das paredes com aberturas. Dessa forma, a inserção de armaduras nas juntas de assentamento com a presença dos grampos configura uma alternativa tecnológica racionalizada para as edificações com aberturas pequenas (menores que $1,20 \mathrm{~m}$ ) e sem incidência de elevados carregamentos sobre as lajes;

(c) as vergas do tipo VL, VLT e VGL indicaram modos de ruptura provocados pelo esforço cortante. As fissurações diagonais em direção aos apoios, cortando os blocos ao longo das juntas de argamassa, indicaram que a tensão de aderência na interface bloco e argamassa foi superada;

(d) por meio do estudo comparativo do dimensionamento de vergas ao cisalhamento, utilizando-se as prescrições propostas pelo código europeu e pelo brasileiro, observou-se que a metodologia europeia resultou em valores mais conservadores para o esforço cortante resistente; e

(e) o valor do esforço cortante teórico último para as vergas tipo VGL, calculado a partir das recomendações da NBR 15812-1 (ABNT, 2010), foi inferior à força cortante média de ruptura dos modelos ensaiados. A verificação do esforço cortante teórico último dos modelos VL e VLT (tanto pelo código europeu quanto pelo brasileiro), admitindo-se os mesmos limites de resistência ao cisalhamento estabelecido para as vergas grauteadas, permitiu concluir que, para o dimensionamento de vergas armadas na junta de assentamento, esses limites não podem ser aplicados, necessitando-se de um valor menor.

Tabela 16 - Valor do esforço cortante último

\begin{tabular}{c|c|c|c|c}
\hline & $\begin{array}{c}f_{v k}=\left(\mathbf{2 d} / \mathbf{a}_{\mathbf{v}}\right) \cdot f_{v k} \\
(\mathbf{M P a})\end{array}$ & $\begin{array}{c}f_{v k} \\
(\mathbf{M P a}) \\
\text { limite }\end{array}$ & $\begin{array}{c}\boldsymbol{V}_{u t \mathbf{t}} \\
\text { (resistido pela } \\
\text { alvenaria em kN) }\end{array}$ & $\begin{array}{c}\boldsymbol{V}_{u t} \\
\text { (resistido pela } \\
\text { alvenaria e } \\
\text { estribos em kN) }\end{array}$ \\
\hline VL & 0,77 & 0,7 & 39,20 & - \\
\hline $\begin{array}{c}\text { VLT } \\
\text { VGL } \\
(2010)\end{array}$ & 0,77 & 0,7 & 39,20 & - \\
\hline $\begin{array}{c}\text { VGL } \\
\text { NBR 15961-1 } \\
(2011)\end{array}$ & 0,76 & 0,7 & 14,70 & - \\
\hline
\end{tabular}

Fonte: NBRs 15812-1 (ABNT, 2010a) e 15961-1 (ABNT, 2011). 
Tabela 17 - Valor do esforço cortante último

\begin{tabular}{c|c|c|c}
\hline & $\begin{array}{c}f_{v k}(\mathbf{M P a}) \\
\text { limite }\end{array}$ & $\begin{array}{c}\boldsymbol{V}_{u t \boldsymbol{l}}(\text { resistido pela } \\
\text { alvenaria }-\mathbf{k N})\end{array}$ & $\begin{array}{c}\boldsymbol{V}_{u t}(\text { resistido pela alvenaria } \\
\text { e estribos }-\mathbf{k N})\end{array}$ \\
\hline VL & 0,2 & 11,20 & - \\
VLT & 0,2 & 11,20 & 19,68 \\
VGL & 0,2 & 10,64 & - \\
\hline
\end{tabular}

Fonte: segundo o Eurocode 6 (EN, 2005).

\section{Referências}

ASSOCIAÇÃO BRASILEIRA DE NORMAS TÉCNICAS. NBR 12142: concreto: determinação da resistência à tração na flexão de corpos de prova prismáticos. Rio de Janeiro. 2010d. 5 p.

ASSOCIAÇÃO BRASILEIRA DE NORMAS TÉCNICAS. NBR 13276: argamassa para assentamento e revestimento de paredes e tetos: preparo da mistura e determinação do índice de consistência. Rio de Janeiro. 2005b. 3 p.

\section{ASSOCIAÇÃO BRASILEIRA DE NORMAS} TÉCNICAS. NBR 13279: argamassa para assentamento e revestimento de paredes e tetos: determinação da resistência à tração na flexão e à compressão. Rio de Janeiro. 2005c. 9 p.

\section{ASSOCIAÇÃO BRASILEIRA DE NORMAS}

TÉCNICAS. NBR 15270-2: componentes cerâmicos: parte 2: blocos cerâmicos para alvenaria estrutural: terminologia e requisitos. Rio de Janeiro. 2005d. 11 p.

\section{ASSOCIAÇÃO BRASILEIRA DE NORMAS TÉCNICAS. NBR 15270-3: componentes cerâmicos: parte 3: blocos cerâmicos para alvenaria estrutural e de vedação: métodos de ensaio. Rio de Janeiro. 2005a. 27 p.}

\section{ASSOCIAÇÃO BRASILEIRA DE NORMAS} TÉCNICAS. NBR 15961-1: alvenaria estrutural: blocos de concreto. Parte 1: Projetos. Rio de Janeiro. 2011. 41 p.

\section{ASSOCIAÇÃO BRASILEIRA DE NORMAS} TÉCNICAS. NBR 15812-1: alvenaria estrutural: blocos cerâmicos: parte 1: projetos. Rio de Janeiro. 2010a. 41 p.

\section{ASSOCIAÇÃO BRASILEIRA DE NORMAS} TÉCNICAS. NBR 15812-2: alvenaria estrutural: blocos cerâmicos: parte 2: execução e controle de obras. Rio de Janeiro. 2010b. 28 p.

ASSOCIAÇÃO BRASILEIRA DE NORMAS TÉCNICAS. NBR 5738: concreto: procedimento para moldagem e cura de corpos de prova. Rio de Janeiro. 2003. 6 p.
ASSOCIAÇÃO BRASILEIRA DE NORMAS TÉCNICAS. NBR 5739: concreto: ensaios de compressão de corpos de prova cilíndricos. Rio de Janeiro. 2007. 9 p.

\section{ASOCIACIÓN MERCOSUR DE}

NORMALIZACIÓN. NM 248: agregados: determinação da composição granulométrica. 2001. 6 p.

\section{ASOCIACIÓN MERCOSUR DE}

NORMALIZACIÓN. NM 45: agregados: determinação da massa unitária e do volume de vazios. $2006.8 \mathrm{p}$.

\section{ASOCIACIÓN MERCOSUR DE}

NORMALIZACIÓN. NM 52: agregado miúdo: determinação de massa específica e massa específica aparente. 2009a. 6 p.

\section{ASOCIACIÓN MERCOSUR DE}

NORMALIZACIÓN. NM 53: agregado graúdo: determinação de massa específica e massa aparente. 2009b. 8 p.

\section{ASOCIACIÓN MERCOSUR DE}

NORMALIZACIÓN. NM 23: cimento portland: determinação e massa específica. 2000. 5 p.

\section{BRITISH STANDARDS INSTITUTION. BSI}

5628: part 1: code of practice for use of masonry: structural use of unreinforced masonry. London, 1992. $58 \mathrm{p}$.

COSTA NETO, P. L. O. Estatística. São Paulo: Edgard Blücher, 1977. 264 p.

\section{EUROPEAN STANDARD. EN 1996-1-1:}

Eurocode 6: design of masonry structures: part 11: general rules for reinforced and unreinforced masonry structures. 2005. $123 \mathrm{p}$.

FONSECA, J. S.; MARTINS, G. A. M. Curso de Estatística. 3. ed. São Paulo: Atlas, 1982. 286 p.

HEINECK, L.F.M. Efeito Continuidade e Efeito Concentração no Aumento da Produtividade nas Alvenarias. In: SIMPÓSIO DE DESEMPENHO DE MATERIAIS E COMPONENTES DE CONSTRUÇÃO CIVIL, 3., Florianópolis, 1991. Anais... Florianópolis, 1991. p. 67-75. 
LIMA, L. Alvenaria Racional: saiba como o boom de habitações populares e a nova norma de alvenaria estrutural impactam as obras.

Entrevistador: Gisele C. Cichinelli. Revista

Construção e Mercado, n. 109, ago. 2010.

MAMEDE, F. C. Utilização de Pré-Moldados em Edifícios de Alvenaria Estrutural. 187 f. São

Carlos, 2001. Dissertação (Mestrado em Engenharia de Estruturas) - Escola de Engenharia de São Carlos, Universidade de São Paulo, São Carlos, 2001.

NEIS, V. V.; LOEFFLER, R. J. Results of Ultimate Flexural and Shear Tests on Reinforced Masonry beams. In: CANADIAN MASONRY SYMPOSIUM, 3., Edmonton, 1983. Proceedings... Alberta, 1983. p. 13/1-13/16.

OLIVEIRA, A. F. G. Testes Estatísticos Para Comparação de Médias. Revista Eletrônica Nutritime, v. 5, n. 6, p. 777-788, nov./dez. 2008.

PARSEKIAN, G. A.; SOARES, M. M. Alvenaria Estrutural em Blocos Cerâmicos: projeto, execução e controle. São Paulo: O Nome da Rosa, 2010. 238 p.

PARSEKIAN, G. A.; HAMID, A. A.; DRYSDALE, R. G. Comportamento e Dimensionamento de Alvenaria Estrutural. São Carlos: EdUFSCar, 2012. v. 1, 625 p.
PRUDÊNCIO JÚNIOR, L. R. Resistência à Compressão da Alvenaria e Correlação Entre a Resistência de Unidades, Prismas e Paredes. 144 f. Porto Alegre, 1986. Dissertação (Mestrado em Engenharia) - Escola de Engenharia, Universidade Federal do Rio Grande do Sul, Porto Alegre, 1986.

RAMALHO, M. A.; CORRÊA, M. R. S. Projetos de Edifícios de Alvenaria Estrutural. São Paulo: Pini, 2003. 174 p.

RITCHER, C. Qualidade da Alvenaria Estrutural em Habitações de Baixa Renda: uma análise da confiabilidade e da conformidade. $180 \mathrm{f}$. Porto Alegre, 2007. Dissertação (Mestrado em Engenharia) - Escola de Engenharia da Universidade Federal do Rio Grande do Sul, Porto Alegre, 2007.

SÁNCHEZ FILHO, E. S. Alvenaria Estrutural: novas tendências técnicas e de mercado. Rio de Janeiro: Interciência; Senai, 2002. 89 p.

SUTER, G. T.; KELLER, H. Shear Strength of Reinforced Masonry Beams and Canadian Code Implications. In: CANADIAN MASONRY SYMPOSIUM, 1., Calgary, 1976. Proceedings... Calgary, 1976.

Revista Ambiente Construído

Associação Nacional de Tecnologia do Ambiente Construído

Av. Osvaldo Aranha, $99-3^{\circ}$ andar, Centro

Porto Alegre - RS - Brasil

CEP 90035-190

Telefone: +55 (51) 3308-4084

Fax: +55 (51) 3308-4054

www.seer.ufrgs.br/ambienteconstruido

E-mail: ambienteconstruido@ufrgs.br 